\title{
SUPERFACT: A Model Fuel for Studying the Evolution of the Microstructure of Spent Nuclear Fuel during Storage/Disposal
}

\author{
Thierry Wiss ${ }^{1, *(\mathbb{D},}$, Oliver Dieste ${ }^{1,2}{ }^{\mathbb{D}}$, Emanuele De Bona ${ }^{1}$, Alessandro Benedetti ${ }^{1}$, Vincenzo Rondinella ${ }^{1}$ \\ and Rudy Konings 1 \\ 1 Joint Research Centre, European Commission, P.O. Box 2340, 76125 Karlsruhe, Germany; \\ oliver.dieste@kit.edu (O.D.); Emanuele.DE-BONA@ext.ec.europa.eu (E.D.B.); \\ alessandro.benedetti@ec.europa.eu (A.B.); vincenzo.rondinella@ec.europa.eu (V.R.); \\ rudy.konings@ec.europa.eu (R.K.) \\ 2 Institute for Nuclear Waste Disposal (INE), Karlsruher Institute of Technology (KIT), Campus North, \\ Hermann-von-HelmholtzPlatz 1, 76344 Eggenstein-Leopoldshafen, Germany \\ * Correspondence: Thierry.wiss@ec.europa.eu
}

Citation: Wiss, T.; Dieste, O.; De Bona, E.; Benedetti, A.; Rondinella, V.; Konings, R. SUPERFACT: A Model Fuel for Studying the Evolution of the Microstructure of Spent Nuclear Fuel during Storage/Disposal. Materials 2021, 14, 6538. https://doi.org/ $10.3390 /$ ma14216538

Academic Editor: Salvatore Tudisco

Received: 10 August 2021

Accepted: 25 October 2021

Published: 30 October 2021

Publisher's Note: MDPI stays neutral with regard to jurisdictional claims in published maps and institutional affiliations.

Copyright: (c) 2021 by the authors. Licensee MDPI, Basel, Switzerland. This article is an open access article distributed under the terms and conditions of the Creative Commons Attribution (CC BY) license (https:/ / creativecommons.org/licenses/by/ $4.0 /)$.

\begin{abstract}
The transmutation of minor actinides (in particular, Np and Am), which are among the main contributors to spent fuel $\alpha$-radiotoxicity, was studied in the SUPERFACT irradiation. Several types of transmutation $\mathrm{UO}_{2}$-based fuels were produced, differing by their minor actinide content $\left({ }^{241} \mathrm{Am},{ }^{237} \mathrm{~Np}, \mathrm{Pu}\right)$, and irradiated in the Phénix fast reactor. Due to the high content in rather short-lived alpha-decaying actinides, both the archive, but also the irradiated fuels, cumulated an alpha dose during a laboratory time scale, which is comparable to that of standard LWR fuels during centuries/millenaries of storage. Transmission Electron Microscopy was performed to assess the evolution of the microstructure of the SUPERFACT archive and irradiated fuel. This was compared to conventional irradiated spent fuel (i.e., after years of storage) and to other ${ }^{238} \mathrm{Pu}$-doped $\mathrm{UO}_{2}$ for which the equivalent storage time would span over centuries. It could be shown that the microstructure of these fluorites does not degrade significantly from low to very high alpha-damage doses, and that helium bubbles precipitate.
\end{abstract}

Keywords: alpha-damage; SUPERFACT irradiation; spent fuel; microstructure; helium

\section{Introduction}

Aside from plutonium, the radiotoxicity of spent fuel during the first centuries of storage/disposal is largely due to Minor Actinides (MA), particularly americium. [1].

In the case of spent fuel reprocessing and minor actinide separation, americium can be transmuted in fast reactors in so-called Minor Actinide Bearing Blankets (MABB), therefore reducing the global inventory of High Level Waste (HLW). An initial transmutation experiment in this sense was performed in the SUPERFACT irradiation project during the mid-1980s [2], when $\mathrm{UO}_{2}$-based fuels with a different content of americium, as well as other actinides, were irradiated in the Phénix fast reactor. The project investigated the possibility of transmuting those minor actinides into less dangerous elements and at the same time obtain energy from waste. Two different sets of samples were prepared: one set with a low content of MAs (homogeneous mode), and another with a high content of MA (heterogeneous mode). These samples were irradiated up to a burnup of 6.5 at $\%$ in the case of the homogeneous, and 4.5 at $\%$ for the heterogeneous.

Some SUPERFACT fuels recently examined by Transmission Electron Microscopy (TEM) showed remarkable behaviour in terms of radiation damage [3]. It could be shown that no micro-craking occurred despite a high level of damage and substantial radiogenic helium formation, in contrast with aged $\mathrm{PuO}_{2}$, for example.

Samples from the SUPERFACT fuel with 20 at $\%$ americium and 20\% neptunium content have been archived for 27 years since their production; irradiated rods have 
been sampled and post-irradiation examinations performed soon after the irradiation. Recently, both irradiated and archive samples have been analysed to study their different microstructures. All samples selected in this study have various compositions in terms of MA content but share the same fluorite structure. They also differ from real spent fuels in terms of the presence of fission products and the stoichiometry of some. Typically, with high MA content, materials are sub-stoichiometric. For the irradiated SUPERFACT fuel with a high MA content (designated SF14), it is assumed that the high temperature reached during irradiation anneals most defects, and the calculated damage (dpa) is that from end of irradiation (EOI) until the time of investigation. The damage level attained by this sample in particular is beyond anything previously studied for ${ }^{238} \mathrm{Pu}$-doped $\mathrm{UO}_{2}$ samples.

Electron Energy Loss Spectroscopy (EELS) was employed to determine the evolution of the composition of these materials to calculate the cumulated alpha dose. TEM/Scanning TEM (STEM), on the other hand, allowed one to examine the microstructure as a function of cumulated alpha dose.

Figure 1 shows a 3D representation of alpha-recoil cascades into a volume of $10^{6} \mathrm{~nm}^{3}$ generated in one day for the SF14 sample. The cascades were calculated using SRIM2013 [4] and a macro written to allow for a space and time distribution of the cascades. The path (blue fading to white at the end of range) of the recoil nucleus, ${ }^{237} \mathrm{~Np}$, from a decaying ${ }^{241} \mathrm{Am}$ is represented in Figure 1a as well as the corresponding alpha particle (orange). In Figure $1 \mathrm{~b}$ the path of the ${ }^{237} \mathrm{~Np}$ recoil is again represented in blue, while the red spots are the displaced atoms from the recoil cascades. For the calculation only $\mathrm{U}, \mathrm{Np}, \mathrm{Pu}, \mathrm{Am}$, and $\mathrm{O}$ atoms were included and a mean displacement energy of $40 \mathrm{eV}$ for the cations and $20 \mathrm{eV}$ for $\mathrm{O}$ were used [5]. These values, as used in the Kinchin-Pease approach [6] to determine the damage as calculated with SRIM, were not precisely assessed for all the actinides, but were generally taken as close to those for $\mathrm{U}$ and $\mathrm{O}$ in $\mathrm{UO}_{2}$. It was, for example, shown that for $\mathrm{Pu}$ in $(\mathrm{U}, \mathrm{Pu}) \mathrm{O}_{2}$ the values could be slightly lower [7], as determined by the molecular dynamic calculation of the cascades.

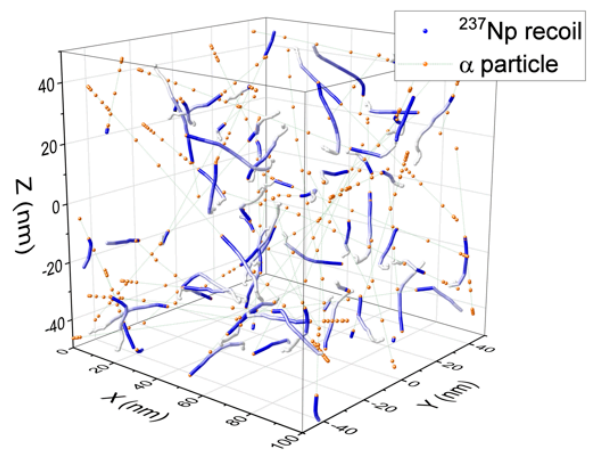

(a)

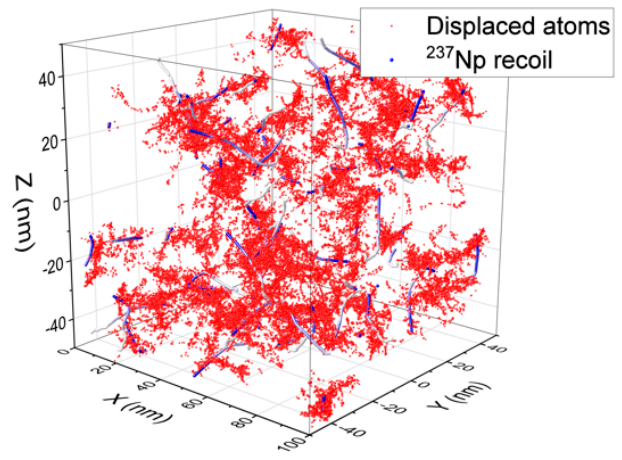

(b)

Figure 1. Simulation made with SRIM reflecting the level of damage that occurred in an SF14 cube with a $100 \mathrm{~nm}$ side over 1 day, i.e., $1.6 \times 10^{-2} \mathrm{dpa}$. (a) ${ }^{237} \mathrm{~Np}$ recoil atoms (blue dots) and alpha particle paths (orange dots). (b) Recoil cascades (red dots) and ${ }^{237} \mathrm{~Np}$ recoil atoms (blue dots).

${ }^{238} \mathrm{Pu}$ has been used over many years in several studies to accelerate damage accumulation in materials studied for the immobilization of high-level waste or for the burning of excess plutonium in nuclear fuel [8-10]. In their paper, Burakov et al. studied immobilization matrices such as monazite, pyrochlore, zircon, or cubic zirconia doped with ${ }^{238} \mathrm{Pu}$ (same structure as $\mathrm{UO}_{2}$ ), which showed a good resistance to damage by a competing process of damage build-up and annealing processes, whereas in $\mathrm{PuO}_{2}$ (with approximately $10 \mathrm{at} \%{ }^{238} \mathrm{Pu}$ ) it was less evident that annealing occurred [11]. More studies have been performed with ${ }^{238} \mathrm{Pu}$-doped $\mathrm{UO}_{2}$ synthesized to mimic nuclear spent fuel for the same purpose of accelerating the damage accumulation. Some of the observations made are reported here to cover other damage ranges and/or different compositions than 
the SUPERFACT samples. For these ${ }^{238} \mathrm{Pu}$-doped $\mathrm{UO}_{2}$ samples, several investigations were reported in [12-18]. Among the properties studied in the aforementioned works were lattice parameter evolution (an increase of $0.4 \%$ until saturation can be anticipated), microstructure evolution (formation of dislocation loops increasing in size and density), the increase in Vickers hardness, the formation of nanometric helium bubbles, and the decrease in thermal conductivity. For these properties, it could be shown that the linearity applies for systems having similar alpha activity to spent fuels, and to some with activities even two orders of magnitude higher. In this paper, we have extended the study to systems (i.e., the SUPERFACT samples) with high alpha activity due to their even larger minor actinide content, among them ${ }^{241} \mathrm{Am}$.

The cumulated damage at the time of investigation and the equivalent storage time for different types of fuels are shown in Figure 2 and reported in Table 1 (for better readability).

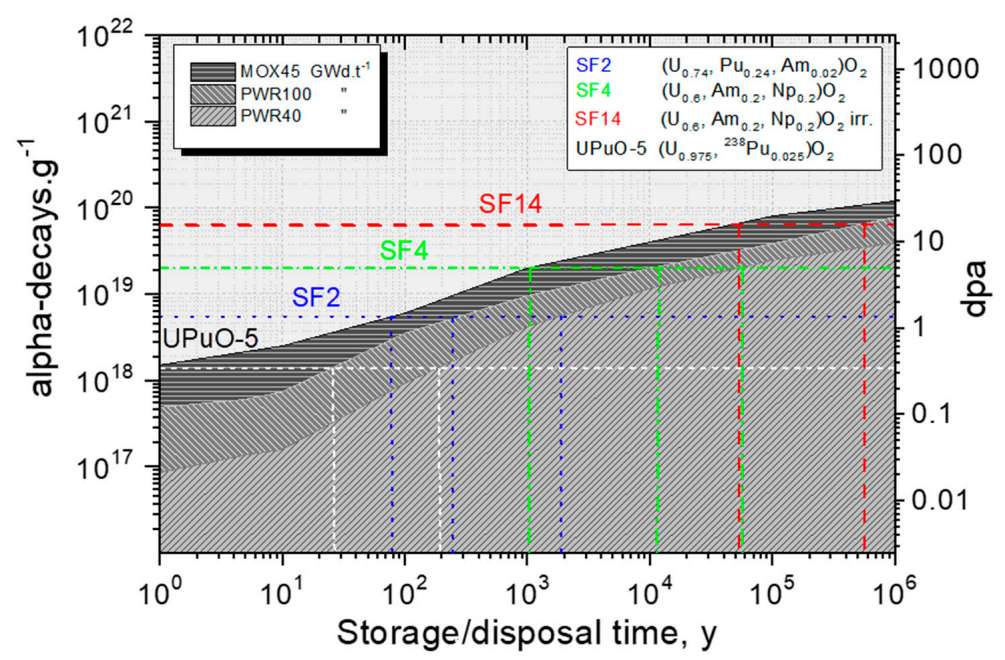

Figure 2. Evolution of the alpha dose and damage (expressed as dpa) in three types of fuels: PWR fuel with $40 \mathrm{GWd} . \mathrm{t}^{-1}$, high burnup PWR fuel with $100 \mathrm{GWd} \cdot \mathrm{t}^{-1} \mathrm{HM}$, and MOX with $45 \mathrm{GWd} . \mathrm{t}^{-1}$. The figure also shows the equivalent doses/damage of four of the samples of this study that will be discussed in more detail in the Materials and Methods section.

Table 1. Samples studied with the cumulated alpha dose and damage and their equivalent storage time for several types of LWR fuels.

\begin{tabular}{|c|c|c|c|c|c|}
\hline \multirow{2}{*}{ Sample } & \multirow{2}{*}{$\alpha$-Decays $\left[\mathrm{g}^{-1}\right]$} & \multirow{2}{*}{ Dpa } & $\begin{array}{l}\text { Eq. Standard LWR } \\
(40 \mathrm{GWd} / \mathrm{t})\end{array}$ & $\begin{array}{l}\text { Eq. HBU LWR } \\
(100 \mathrm{GWd} / \mathrm{t})\end{array}$ & $\begin{array}{l}\text { Eq. MOX LWR } \\
(45 \mathrm{GWd} / \mathrm{t})\end{array}$ \\
\hline & & & \multicolumn{3}{|c|}{ Storage Time (Years) } \\
\hline SF2 $\left(\mathrm{U}_{0.74}, \mathrm{Pu}_{0.24}, \mathrm{Am}_{0.02}\right) \mathrm{O}_{2}$ & $5.5 \times 10^{18}$ & 1.3 & 2000 & 250 & 80 \\
\hline $\mathrm{SF} 4\left(\mathrm{U}_{0.6}, \mathrm{Am}_{0.2}, \mathrm{~Np}_{0.2}\right) \mathrm{O}_{2}$ & $2 \times 10^{19}$ & 4.9 & 55,000 & 12,000 & 1000 \\
\hline $\mathrm{SF} 14\left(\mathrm{U}_{0.6}, \mathrm{Am}_{0.2}, \mathrm{~Np}_{0.2}\right) \mathrm{O}_{2} \mathrm{irr}$ & $6.4 \times 10^{19}$ & 15.9 & $>1,000,000$ & 550,000 & 60,000 \\
\hline $\mathrm{UPuO}-10\left(\mathrm{U}_{0.9},{ }^{238} \mathrm{Pu}_{0.1}\right) \mathrm{O}_{2}$ & $1.6 \times 10^{19}$ & 4 & 30,000 & 5000 & 600 \\
\hline $\mathrm{UPuO}-5\left(\mathrm{U}_{0.975},{ }^{238} \mathrm{Pu}_{0.025}\right) \mathrm{O}_{2}$ & $1.4 \times 10^{18}$ & 0.33 & 200 & 25 & 1 \\
\hline
\end{tabular}

\section{Materials and Methods}

\subsection{Sample Production (SF2, SF4; Archive, ${ }^{238} \mathrm{Pu}$-Doped $\mathrm{UO}_{2}$ )}

All the SUPERFACT fuels were prepared by a combination of gel-supported precipitation (GSP) and powder processing methods [19]. The feed stock was uranyl nitrate and the plutonium, americium, and neptunium dioxides, which were available as powders. Uranyl nitrate was dissolved in water, while nitric acid (ca. 3M) was the solvent for $\mathrm{AmO}_{2}$ as well as for $\mathrm{PuO}_{2}$ and $\mathrm{NpO}_{2}$, at a higher concentration (14M) in the latter case. The stock 
solutions were analysed and mixed as specified by the chemical composition of the desired fuel. The external gelation route was the GSP process used for SUPERFACT.

The most critical step was to increase the viscosity of the solution by the adding specific thickeners. The resultant broth solution was then passed through a dispersion device to prepare droplets via a high-speed rotating cup, which were collected in an ammonia bath. Once dried, the obtained particles were calcined to provide the dioxide feed powders.

Further processing of the fuel followed conventional compaction and sintering steps. Compaction was performed using a Bussmann uniaxial hydraulic press, furnished with a floating die to minimise pressure and avoid density in-homogeneities through the sample. The furnace was a ceramic tube furnace. As expected, auto-radiographies confirmed an (almost) uniform distribution of the actinides in all fuels. The pellets had a diameter of approximately $5.4 \mathrm{~mm}$ and a density of approximately $96 \%$ of the theoretical density. Homogeneous grain sizes were observed by ceramography, and autoradiography confirmed a rather homogeneous MA distribution.

The $\left(\mathrm{U}_{\mathrm{x}}, \mathrm{Pu}_{1-\mathrm{x}}\right) \mathrm{O}_{2}$ samples were prepared according to a similar sol-gel process described in $[14,19]$.

All the samples were prepared by a sol-gel process, resulting in a homogeneous distribution of the elements. Some details, such as on the isotopic composition of the various samples, can be found in Table 2, and were particularly important for determining the total cumulated doses in our samples. The elemental composition of the SUPERFACT samples was evaluated by EELS and compared with the initial composition (see Section 2.4 and Figure A1 in Appendix A) or for the irradiated material (SF14) with the calculated theoretical composition:

1. High burnup.

2. Sample irradiated in the Phénix reactor.

Table 2. Elemental and isotopic composition of the three SUPERFACT samples at the starting point of their storage and their theoretical elemental composition at the time of their study, together with the elemental analyses performed with EELS. At the bottom of the table, the dpa are calculated for each of the SUPERFACT samples.

\begin{tabular}{|c|c|c|c|c|c|c|c|c|c|c|c|c|c|c|c|c|}
\hline \multirow[b]{2}{*}{ Isotope } & \multirow{12}{*}{ 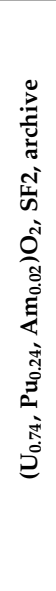 } & \multicolumn{2}{|c|}{$\begin{array}{c}\text { Start } \\
(31 / 08 / 1988)\end{array}$} & \multicolumn{2}{|c|}{$\begin{array}{c}\text { Study } \\
(21 / 10 / 2015)\end{array}$} & \multirow{12}{*}{ 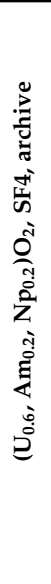 } & \multicolumn{2}{|c|}{$\begin{array}{c}\text { Start } \\
(26 / 10 / 1986)\end{array}$} & \multicolumn{2}{|c|}{$\begin{array}{c}\text { Study } \\
(26 / 06 / 2015)\end{array}$} & \multirow{4}{*}{ 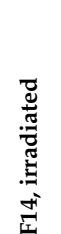 } & \multicolumn{2}{|c|}{$\begin{array}{c}\text { Start } \\
(26 / 10 / 1986)\end{array}$} & \multirow{2}{*}{$\begin{array}{c}\text { EOL } \\
\text { at } \% \\
\text { Isotp. }\end{array}$} & \multicolumn{2}{|c|}{$\begin{array}{c}\text { Study } \\
(06 / 05 / 2015)\end{array}$} \\
\hline & & $\begin{array}{l}\text { at } \% \\
\text { Isotp. }\end{array}$ & $\begin{array}{l}\text { at } \% \\
\text { Elmt. }\end{array}$ & $\begin{array}{l}\text { at } \% \\
\text { Elmt. }\end{array}$ & EELS & & $\begin{array}{l}\text { at } \% \\
\text { Isotp. }\end{array}$ & $\begin{array}{l}\text { at } \% \\
\text { Elmt. }\end{array}$ & $\begin{array}{c}\text { at } \% \\
\text { Elmt. }\end{array}$ & EELS & & $\begin{array}{l}\text { at } \% \\
\text { Isotp. }\end{array}$ & $\begin{array}{c}\text { at } \% \\
\text { Elmt. }\end{array}$ & & $\begin{array}{l}\text { at\% } \\
\text { Elmt. }\end{array}$ & EELS \\
\hline${ }^{235} \mathrm{U}$ & & 0.5 & \multirow{2}{*}{74.4} & \multirow{2}{*}{74.5} & \multirow{2}{*}{75} & & 0.2 & \multirow{2}{*}{59.7} & \multirow{2}{*}{59.7} & \multirow[b]{2}{*}{58} & & 0.1 & \multirow{2}{*}{58.5} & 0.4 & \multirow{2}{*}{57.3} & \multirow[b]{2}{*}{59.5} \\
\hline${ }^{238} U$ & & 73.8 & & & & & 59.5 & & & & & 58.3 & & 54.4 & & \\
\hline${ }^{238} \mathrm{Pu}$ & & 0.3 & \multirow{5}{*}{23.5} & \multirow{5}{*}{21.8} & \multirow{5}{*}{22} & & - & \multirow{5}{*}{-} & \multirow{5}{*}{-} & \multirow{5}{*}{-} & \multirow{8}{*}{ 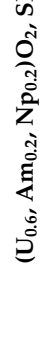 } & 8.1 & \multirow{5}{*}{11.9} & 8.8 & \multirow{5}{*}{14.3} & \multirow{5}{*}{11} \\
\hline${ }^{239} \mathrm{Pu}$ & & 14.4 & & & & & - & & & & & 2.8 & & 3.2 & & \\
\hline${ }^{240} \mathrm{Pu}$ & & 5.5 & & & & & - & & & & & 0.2 & & 0.2 & & \\
\hline${ }^{241} \mathrm{Pu}$ & & 2.1 & & & & & - & & & & & - & & 0.014 & & \\
\hline${ }^{242} \mathrm{Pu}$ & & 1.1 & & & & & - & & & & & 0.8 & & 0.9 & & \\
\hline${ }^{241} \mathrm{Am}$ & & 2.2 & \multirow[b]{2}{*}{2.2} & \multirow{2}{*}{3.6} & \multirow{2}{*}{3} & & 19.0 & \multirow{2}{*}{19.0} & & & & 14.5 & & 11.3 & & \\
\hline${ }^{242} \mathrm{Am}$ & & - & & & & & - & & 18.1 & 17 & & 0.6 & 15.1 & & 13.6 & 14.1 \\
\hline${ }^{237} \mathrm{~Np}$ & & - & - & 0.1 & - & & 21.3 & 21.3 & 22.2 & 25 & & 14.5 & 14.5 & 17.1 & 14.8 & 15.4 \\
\hline $\mathrm{dpa}^{1}$ & & & & & & & & & & & & & & $15.9 \mathrm{dpa}$ & & \\
\hline
\end{tabular}

1 The dpa values were calculated by the theoretical isotopic composition of the sample and may be subject to errors due to their local distribution, in particular for the scale of the TEM samples. For a better reading, particularly for time correspondence with spent fuel, the calculated values were kept without introducing errors. In particular, the sample with the largest possible error (SF14) corresponded to a standard burnup of spent fuel of more than 1 million years. It was rather more important to highlight the time scale than precise values.

\subsection{Irradiation Condition of SF14}

SUPERFACT-1 irradiation took place in the Phénix fast reactor from October 1986 to January 1988 in the same outer position (4th crown) of the internal core of the reactor. The sample used in this study (SF14) originated before irradiation, from the same batch as SF4. The irradiation duration was of 382 Equivalent Full Power Days (EFPD) with a nominal flux of $5.8 \times 10^{19} \mathrm{n} \cdot \mathrm{m}^{-2} \mathrm{~s}^{-1}$, hence a fluence of $2 \times 10^{27} \mathrm{n} \cdot \mathrm{m}^{-2}$ at the end of irradiation. 
The equivalent burnup achieved was $4.1 \mathrm{at} \%\left(38 \mathrm{GWd} / \mathrm{t}_{\mathrm{HM}}\right)$ and the Ti-Ti15 clad reached a dose of $52 \mathrm{dpa}$. The clad temperature remained in the range of $570-640{ }^{\circ} \mathrm{C}$ and the maximal centre temperature was $1920^{\circ} \mathrm{C}$. The linear heat rate ranged from 180 to $290 \mathrm{~W} . \mathrm{cm}^{-1}$.

The actinide transmutation rate was $31 \%$ [20]. The beginning of Pellet Clad Mechanical Interaction (PCMI) was noted, and a very high helium production (60 times standard pins) and release (as suggested by high porosity) was measured. The swelling (axial expansion $2.3 \%$, radial expansion 3.3\%) was moderated and no restructuring (low power) was observed, which normally occurs in fast reactor fuels, as can be seen on the ceramography in Figure 3c. The irradiated pins were studied by various post-irradiation examinations and the results compiled in a joint CEA-JRC report [21].

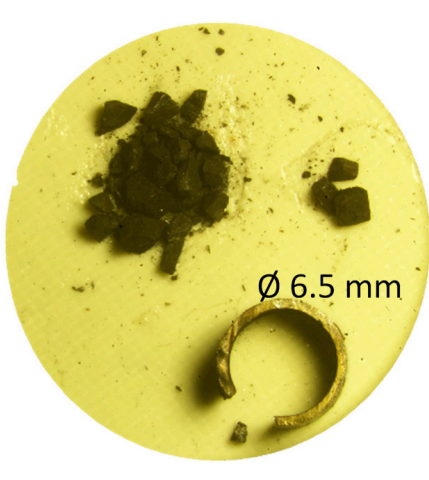

(a)

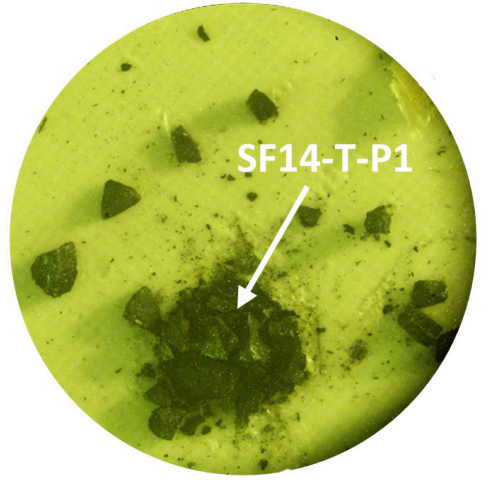

(b)

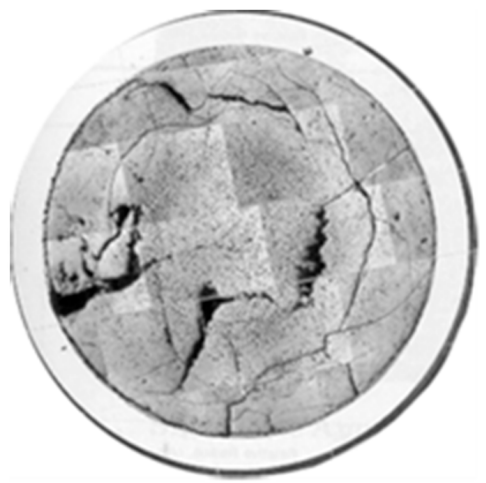

(c)

Figure 3. (a,b) Optical image of de-cladded fuel and the fragment used (SF14-T-P1) in the reported analyses pointed by an arrow, and (c) ceramography of a section of the same rodlet.

The fuel examined by TEM was sampled from a slice cut in an irradiated rod. The cladding was sawed on one side and spread; as the fuel slice that was falling apart maintained its shape, some fragments from an identified radial position could be retrieved. Figure 3a shows a picture taken in the hot cells using a periscope from such a slice of cladding plus fuel, and Figure $3 \mathrm{~b}$ shows the fragments that constituted the fuel piece in their almost original location. In Figure $3 \mathrm{~b}$, the arrow indicates the fragment with the reference SF14-T-P1, which was for the TEM analysis and which corresponded to a position at the centre of the pellet, i.e., irradiated at high temperature (the cladding temperature at end of irradiation was close to $600^{\circ} \mathrm{C}$ ). In Figure 3c, a ceramography from a cut that was close to the sampled specimen shown in Figure 3a revealed that no typical central void formed during the irradiation in fast reactor conditions (the linear power remained low because of the low fissile content).

\subsection{Instruments}

For the present work, we used a FEI Tecnai G2 TEM, equipped with a GATAN Tridiem camera and a GATAN Imaging Filter. The accelerating voltage for the field emission gun was $200 \mathrm{kV}$.

To examine highly active or irradiated nuclear materials, the TEM had to be modified by mounting a glove box around the compustage [22]. In this way, the sample could be transferred from the glove box where it was prepared with the microscope by a La Calhène $\mathrm{DPTE}^{\circledR}$ system.

For the TEM analyses, the samples were lightly grounded from fragments initially collected on the irradiated material or from archival material. A single-tilt TEM holder was used so that the examination could not result in the possibility of selecting a specific zone axis. This was important for the identification and quantitative determination of 
dislocation loops with preferential habit planes. Therefore, no conclusions were made on quantitative aspects (dislocation loop concentration).

The elemental and isotopic analyses were performed after a synthesis of the various types of fuels. In the present work, we used EELS M4 and M5 edges to calculate the ratios between the different actinides present in each sample, using the methodology described in [23]. The results are presented in Section 3 and the original spectra in Appendix A.

The Scanning Electron Microscopy work was performed by using a nuclearized Philips $^{\text {TM }}$ XL40 and a JEOL ${ }^{\text {TM }}$ JM 6300 installed in a shielded hot cell [22].

\subsection{Decay, Doses, Damage}

The samples and their damage dose are listed in Table 1. The NUCLEONICA decay engine [24] was used to calculate the total number of alpha decays from the date of last annealing of the samples until their examination by TEM. The initial isotopic composition was known for the precursors of the different samples and of the irradiated material, SF14, as determined by EPMA [20]. The values of the SUPERFACT samples are reported in Table 2, with the measurement of the elemental composition assessed by EELS.

The dpa parameter was used as a measure of the damage expected in the sample, which on this type of material directly relates to the number of alpha decays by the equation:

$$
\mathrm{dpa}=(1700 \times \alpha) / \mathrm{n}
$$

where $\mathrm{n}$ is the number of atoms in the sample and $\alpha$ is the number of alpha decays. By running an SRIM simulation of displacements produced by an alpha decay of $5.5 \mathrm{MeV}$ in $\mathrm{UO}_{2}$, a multiplying factor of 1700 can be obtained [25] (accounting for the displacements from both the recoil and the alpha particle).

Figure 1 displays 65 alpha decay events taking place in the SF14 sample over one day. Given the error in the SRIM calculation (between 5 and 10\%, see [4]) the difference in energy and mass of the recoil from the various actinides was not considered. As mentioned above, displacement energies were assessed for $\mathrm{U}$ and $\mathrm{O}$ in $\mathrm{UO}_{2}$ as $40 \mathrm{eV}$ and $20 \mathrm{eV}$, respectively [5], and the same values were used by default for the other actinides in this fluorite structure as no measurements had yet been performed.

For the ion-implantations and/or -irradiations discussed later in this paper (most of the damage was studied in $\mathrm{UO}_{2}$ ), we used the correlation between fluence and dpa made by several authors in order to compare their observations with the ones made for our alpha-doped samples. The doping in minor actinides results in a anisotropic distribution of the damage, whereas implantations/irradiations create a damage zone mostly located around the end of the range of the considered ion, corresponding to mainly nuclear energy losses [26]. The TEM observations carried out on implanted samples took place in the highest damaged areas. For example, in the work of Haddad et al. [27], the damage created in $\mathrm{UO}_{2}$ implanted with $260 \mathrm{keV}$ Xe-ions at doses from $10^{13}$ to $4 \times 10^{15}$ ions $\mathrm{cm}^{-2}$ corresponded, on average, to 0.11 to $44 \mathrm{dpa}$, respectively. In the work of Sabathier et al. [28], the investigated TEM areas of $100 \mathrm{~nm}$ thick foils irradiated with $2 \times 10^{16} \mathrm{Au}$-ions cm $\mathrm{cm}^{-2}$ of $4 \mathrm{MeV}$ (initial energy) presented a damage of $1.6 \mathrm{dpa}$ (in this case, the energy loss still had a high electronic contribution resulting in less displacements). He et al. [29] analysed an area implanted with $150 \mathrm{keV}$ (initial energy) of $5 \times 10^{15} \mathrm{Kr}$-ions $\mathrm{cm}^{-2}$ by TEM, which presented an average damage of $13 \mathrm{dpa}$. This last value can be compared with the example of helium implantation. In their work, Belhabib et al. [30] calculated a damage of 0.025 dpa for $10^{15} \mathrm{He}$-ions $\mathrm{cm}^{-2}$ with $50 \mathrm{keV}$ energy. As a last example, one could cite the recent work of Bricout et al. [31] that estimated a damage of 1 dpa in the TEM-investigated area, generated from an initial $900 \mathrm{keV} \mathrm{I-ions} \mathrm{at} \mathrm{a} \mathrm{dose} \mathrm{of} 5 \times 10^{14}$ ions $\mathrm{cm}^{-2}$.

As more studies were performed on ion-implanted/ion-irradiated samples than on doped materials, the agreement between the mentioned damages, expressed in dpa, is important in terms of comparing the radiation effects in the two types of samples. It should also be noted that typical dose rates for damage production are approximately two orders of magnitude larger for implantation than in for doped, self-damaged materials. 
The third type of sample briefly discussed in this paper is irradiated LWR fuels. Alongside the very large damage accumulated during reactor irradiation (approximately 1 dpa per day), it is recognized that additional alpha damage is generated during storage due to the presence of actinides that are already in the material and produced during irradiation [32].

\section{Results}

\subsection{Elemental Evolution of the SUPERFACT Samples with Time: EELS Analysis}

The first of the studied samples, SF2 had a relatively low content of Am and a high content of $\mathrm{Pu}(24 \mathrm{at} \% \mathrm{Pu}$ MOX with 2 at\% Am) material. This sample was not irradiated, and thus the storage time was slightly longer than the irradiated one. The calculated alpha damage was $1.3 \mathrm{dpa}$; although a large amount of $\mathrm{Pu}$ was present, the majority of it was ${ }^{239} \mathrm{Pu}$, with a very long half-life $(24,100$ a), so it did not significantly contribute to alpha damage. ${ }^{240} \mathrm{Pu}$ is also not very alpha active as its half-life is 6561 a. ${ }^{241} \mathrm{Pu}$ decays to ${ }^{241} \mathrm{Am}$ by beta, and thus the alpha damage from this decay was zero. Finally, ${ }^{242} \mathrm{Pu}$ is almost stable, with a half-life of 373,500 a. Overall, among all the plutonium isotopes, only the 0.6 at $\%{ }^{238} \mathrm{Pu}$ would contribute extensively to alpha damage. Thus, the damage was mainly produced by ${ }^{241} \mathrm{Am}$ (original and from ${ }^{241} \mathrm{Pu}$ decay) and ${ }^{238} \mathrm{Pu}$.

The second sample, SF4, contained approximately 20 at $\%$ Am and 20 at $\%$ Np. The composition barely changed after 30 a of storage, but almost all the damage came from ${ }^{241} \mathrm{Am}$ decaying to ${ }^{237} \mathrm{~Np}$ because the former isotope has a relatively short half-life and consequently a relatively high activity. As shown in Table 2, the change from the decayed ${ }^{241} \mathrm{Am}$ into ${ }^{237} \mathrm{~Np}$ did not introduce new isotopes in the composition. Due to the high content in ${ }^{241} \mathrm{Am}$, the cumulated damage in this sample was higher than the previous, reaching $4.9 \mathrm{dpa}$.

The third sample, SF14, was the same as the previously described sample (SF4), but studied after irradiation in the Phénix reactor. During irradiation, the elemental isotopic composition changed, producing a variety of isotopes. Among these newly produced actinides, ${ }^{238} \mathrm{Pu}$ would produce most of the damage due to its short half-life ( $\left.89 \mathrm{y}\right)$, and ${ }^{242} \mathrm{Am}$ (with a short half-life of only $16 \mathrm{~h}$ ) decays to ${ }^{238} \mathrm{Pu}$, increasing the effect of this isotope. Due to the high temperature reached during irradiation, all the possible alpha damage accumulated between the production date and the finish of the irradiation was annealed and all the helium associated released. Notwithstanding, the alpha activity of the ${ }^{242} \mathrm{Am}$ and the ${ }^{238} \mathrm{Pu}$, together with the ${ }^{241} \mathrm{Am}$ and ${ }^{237} \mathrm{~Np}$ (and the ${ }^{241} \mathrm{Am}$ created by the decay of ${ }^{241} \mathrm{Pu}$ via $\beta$ ), led to an accumulated damage of $15.9 \mathrm{dpa}$.

\subsection{SEM Observations}

The 2014 SEM examination of the irradiated sample SF14 did not reveal any changes compared to the first examinations that took place during the post-irradiation examinations in 1991, 3 years after the reactor discharge of the samples, and in 2003, 15 years after the discharge. Figure $4 \mathrm{a}-\mathrm{c}$ shows the SEM images of an area of the irradiated target, which reveals the large porosity that formed, partly attributed to the large quantity of helium formed during irradiation.

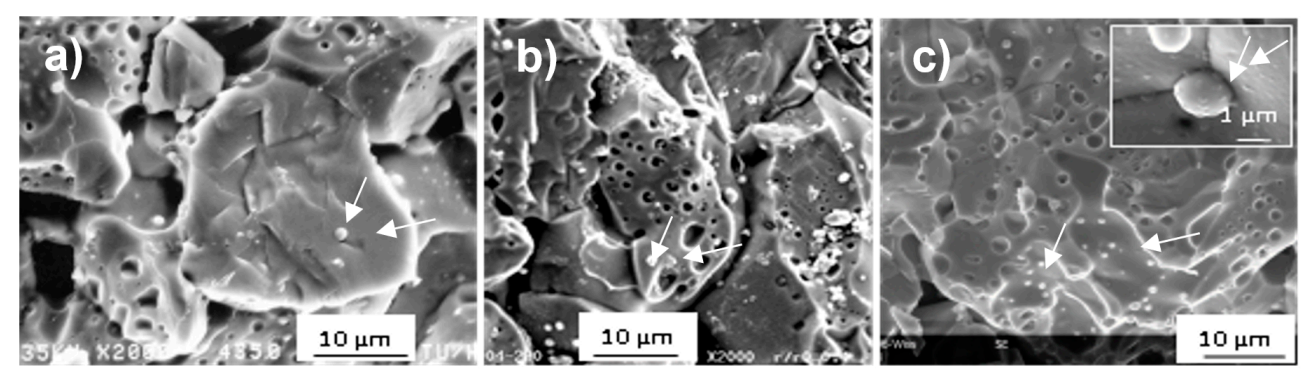

Figure 4. Secondary image of SF14 recorded in (a) 1991, (b) 2003, and (c) 2014. (N.B. the samples SF2 and SF4 were not examined by SEM). 
The small spherical precipitates that can be observed in the three images in Figure 4 (indicated by arrows), highlighted in the inset of Figure $4 c$, are the typical noble metal (Mo, Tc, Ru, Pd, Rh) fission product precipitates formed during irradiation. Their size, on average close to $1 \mu \mathrm{m}$, derives from the high irradiation temperature [33], as was also observed in LWR fuels irradiated at high temperature (see, for example, [34]).

Some of the ${ }^{238} \mathrm{Pu}$-doped samples were periodically observed by SEM and no alteration of the microstructure was observed [35].

\subsection{TEM Observations}

The work presented in this paper focuses on the TEM observations performed on the different samples to assess the microstructure as a function of cumulated alpha doses for which equivalent storage times of real spent fuels are listed in Table 1. The main observations that were obtained from the microstructure examinations are detailed in the next subsections.

\subsubsection{SF2-1.3 Dpa}

The alpha damage on the first sample of study, i.e., SF2 (1.3 dpa), consisted in a large number of dislocation loops. These dislocation loops were found on every particle studied, with sizes that ranged from 5 to $10 \mathrm{~nm}$ (some even larger). Figure 5a,b shows TEM micrographs where dislocation loops can be observed as dark disks. In Figure 5b, helium nano-bubbles can be observed as bright spots typically visible in under-focused conditions. It should be noted that the size of the bubbles looks much larger under these conditions than they were, and their concentration correspondingly smaller. An analogy can be made with the recent study of Onofri et al. [36] showing that, in the case of nano voids, their size and density can vary substantially as a function of the TEM settings.
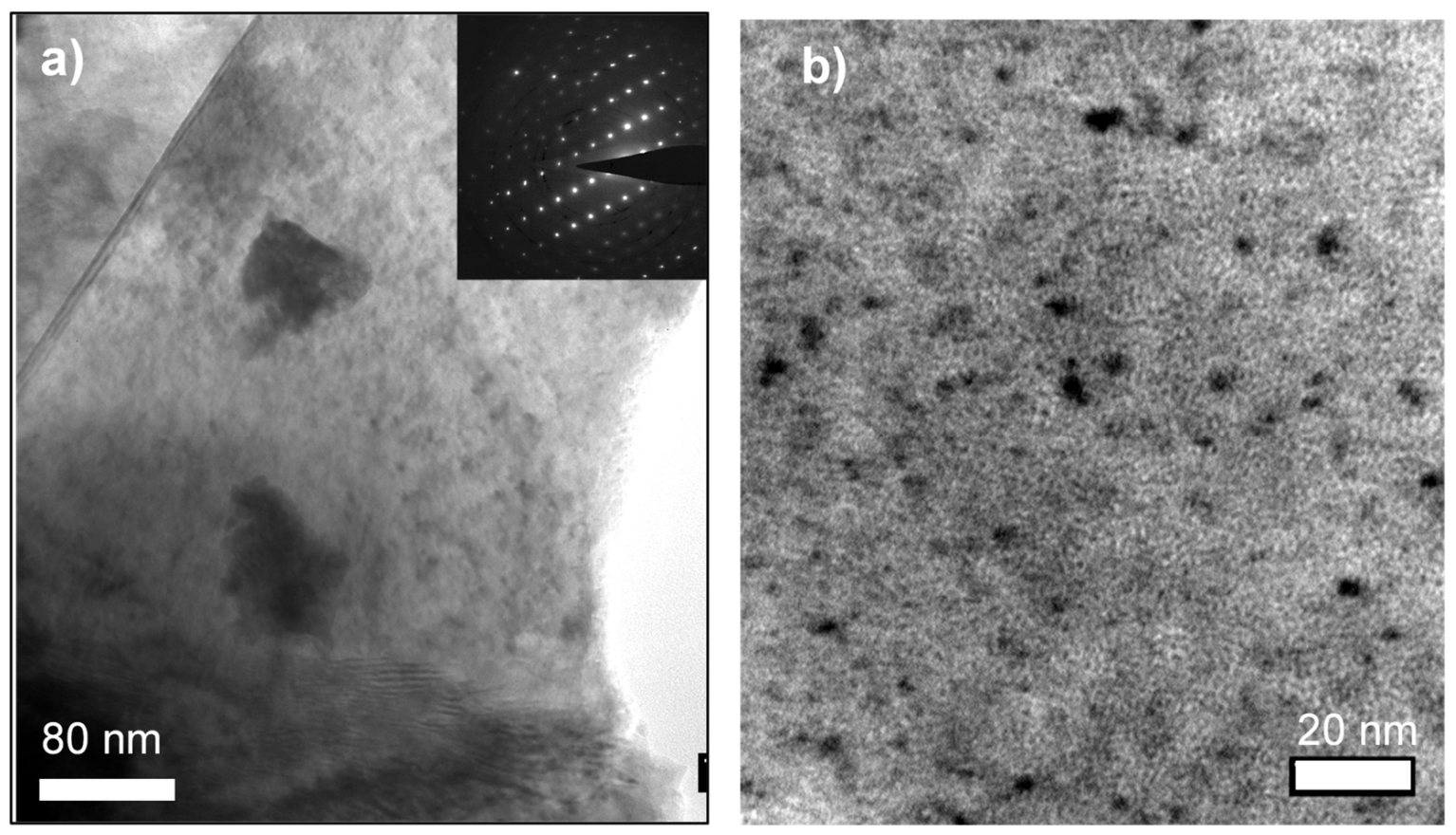

Figure 5. TEM bright field micrographs of the SF2 sample (1.3 dpa) showing: (a) Flat area oriented by the [110] axis showing dislocation loops (dark, circular marks); inset image is the electron diffraction proving the orientation. (b) Higher magnification of dislocation loops with sizes ranging from several nanometers up to ten nanometers (dark marks), together with nanometric over-focused (dark, round spots) and under-focused (light, round spots) helium bubbles. 


\subsubsection{SF4-4.9 Dpa}

In this archive sample, with initially 20 at $\%$ Am and 20 at $\% \mathrm{~Np}$, the accumulated damage consisted of dislocation loops and some small dislocation line segments, as can be seen in Figure 6a,b. The size of the loops is larger than in the SF2 samples, while their concentration appears slightly lower. Figure 6c shows, for example, an image in high resolution of a loop with a diameter of $5 \mathrm{~nm}$. The total damage of almost 5 dpa was substantial, and nanometric bubbles are also observed (white dots on Figure 6b).
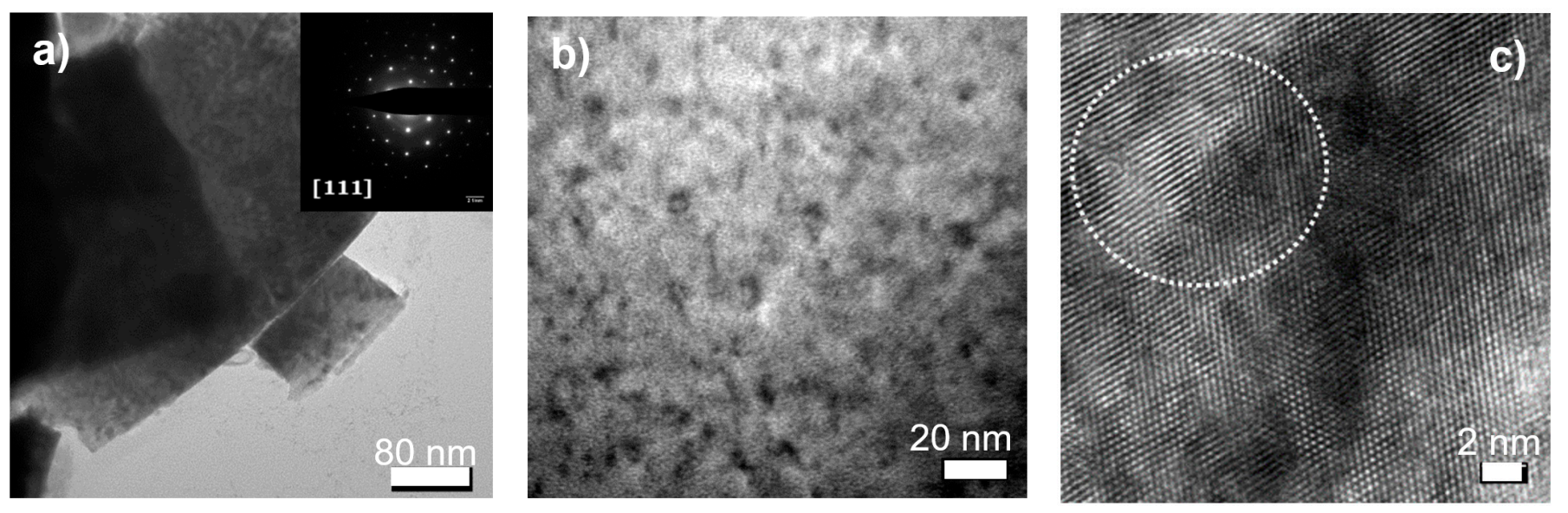

Figure 6. TEM bright field image (a,b) of sample SF4 (4.9 dpa) showing dislocation loops habiting the [111] plane, as shown by the electron diffraction in the inset of (a). (c) HRTEM image showing a single loop of approximately $5 \mathrm{~nm}$ diameter (circled by white dots).

\subsubsection{SF14 Irradiated-15.9 Dpa}

In the irradiated sample that cumulated almost $16 \mathrm{dpa}$ (after irradiation), some larger dislocation loops were visible (Figure 7a,b), while dislocation lines were also present, as can be seen in Figure 7c. In addition, nanometric bubbles were also present, as can be seen in Figure $7 \mathrm{~d}$. The total number of displacements accumulated during irradiation in the reactor could amount to a value as high as $1500 \mathrm{dpa}(1 \mathrm{dpa} /$ day) by considering only the displacements produced by elastic collisions from the fission fragments. The dislocation lines can be formed during irradiation and, in particular, at high temperature where visco-plastic deformation can occur, the observation of dislocations is expected.

\subsubsection{UPuO-5-0.34 Dpa}

In this sample, which was examined 450 days after production and had cumulated approximately $0.34 \mathrm{dpa}$, microstructure analysis revealed the presence of dislocation loops with sizes between 3 and $7 \mathrm{~nm}$, and in some cases as large as $20 \mathrm{~nm}$, as shown in Figure $8 \mathrm{a}-\mathrm{c}$ and as also recently partly reported in [18]. Some further properties (thermal diffusivity, lattice parameter) were measured and reported for this sample recently [14,18]. It could be shown that the microstructure was evolving from an early formation of dislocation loops to larger dislocation loops, reducing in density with increasing dose. The equivalent storage time of a standard LWR fuel would be around 200 years for this sample at the time of this study (see Table 1). 

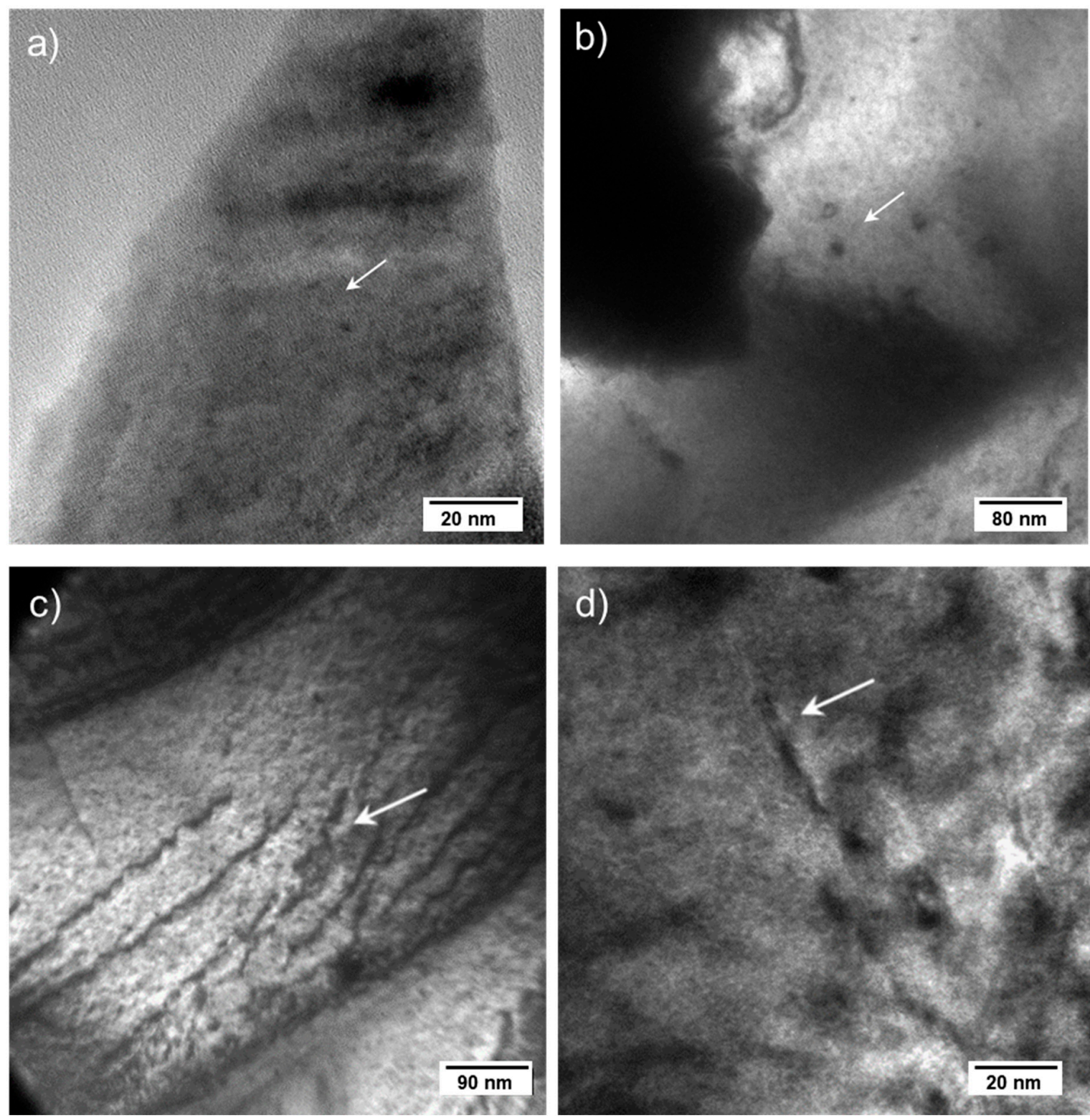

Figure 7. TEM bright field micrographs of sample SF14 (15.9 dpa) showing (a,b) dislocation loops, (c) dislocation lines, (d) dislocations and helium nanometric bubbles (bright spots). All mentioned features are indicated by arrows in the corresponding images.
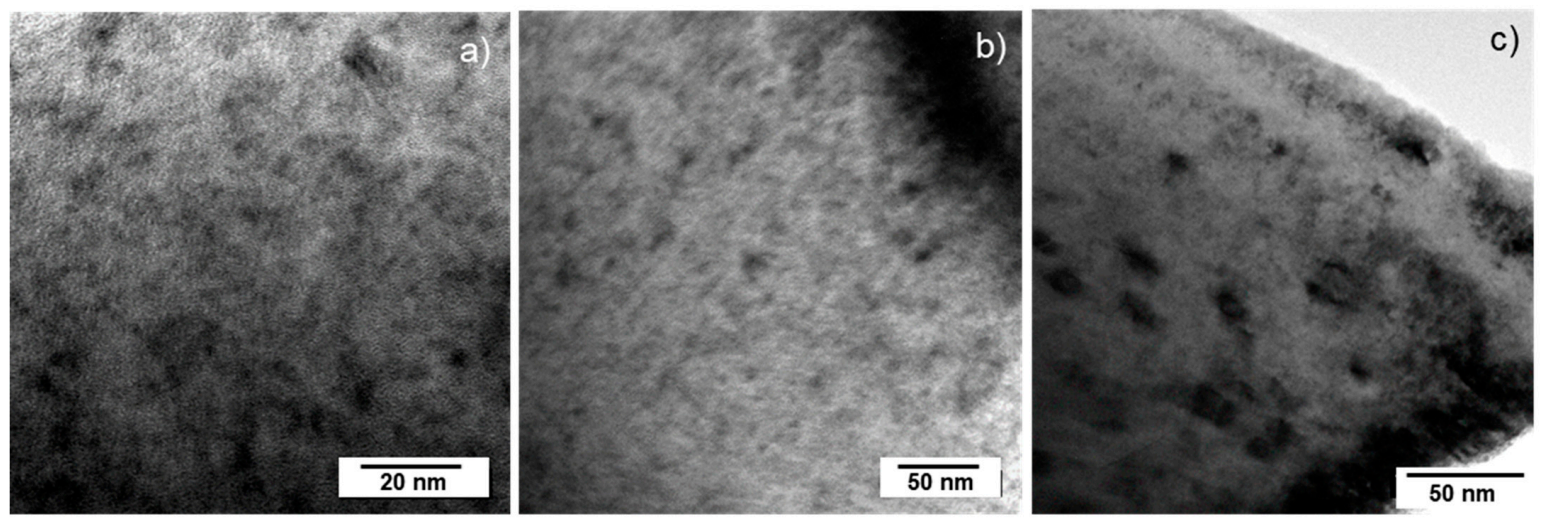

Figure 8. TEM bright field micrographs of sample UPuO-5 (0.34 dpa) showing (a,b) 3-7 nm dislocation loops (c) $20 \mathrm{~nm}$ dislocation loops. 


\subsubsection{UPuO-10-4 Dpa}

The TEM micrographs shown in Figure 9a,b from the ${ }^{238} \mathrm{Pu}$-doped $\mathrm{UO}_{2}$ sample were collected at a damage level of $4 \mathrm{dpa}$. This level of damage is expected after about 30,000 years of storage for a standard LWR fuel. Several results from the microstructure analyses have been reported for this compound $[3,13]$, showing its potential use as a spent fuel surrogate. In the paper of Jonnet et al. [17], a mechanism of coalescence of diffusing interstitial-type dislocation loops was proposed to justify an increase in the size of the loops, which for 4 dpa reach a typical value of $5 \mathrm{~nm}$ compared to 3 and $3.6 \mathrm{~nm}$ for 1.1 and $2 \mathrm{dpa}$, respectively. The dopant concentration $\left({ }^{238} \mathrm{Pu}\right)$ resulted in an activity of $3.76 \times 10^{10} \mathrm{~Bq} \cdot \mathrm{g}^{-1}$, from which the damage rate was found to be $9 \times 10^{-9}$ dpa.s ${ }^{-1}$. Sub-nanometric helium bubbles were observed for the sample with $4 \mathrm{dpa}$.
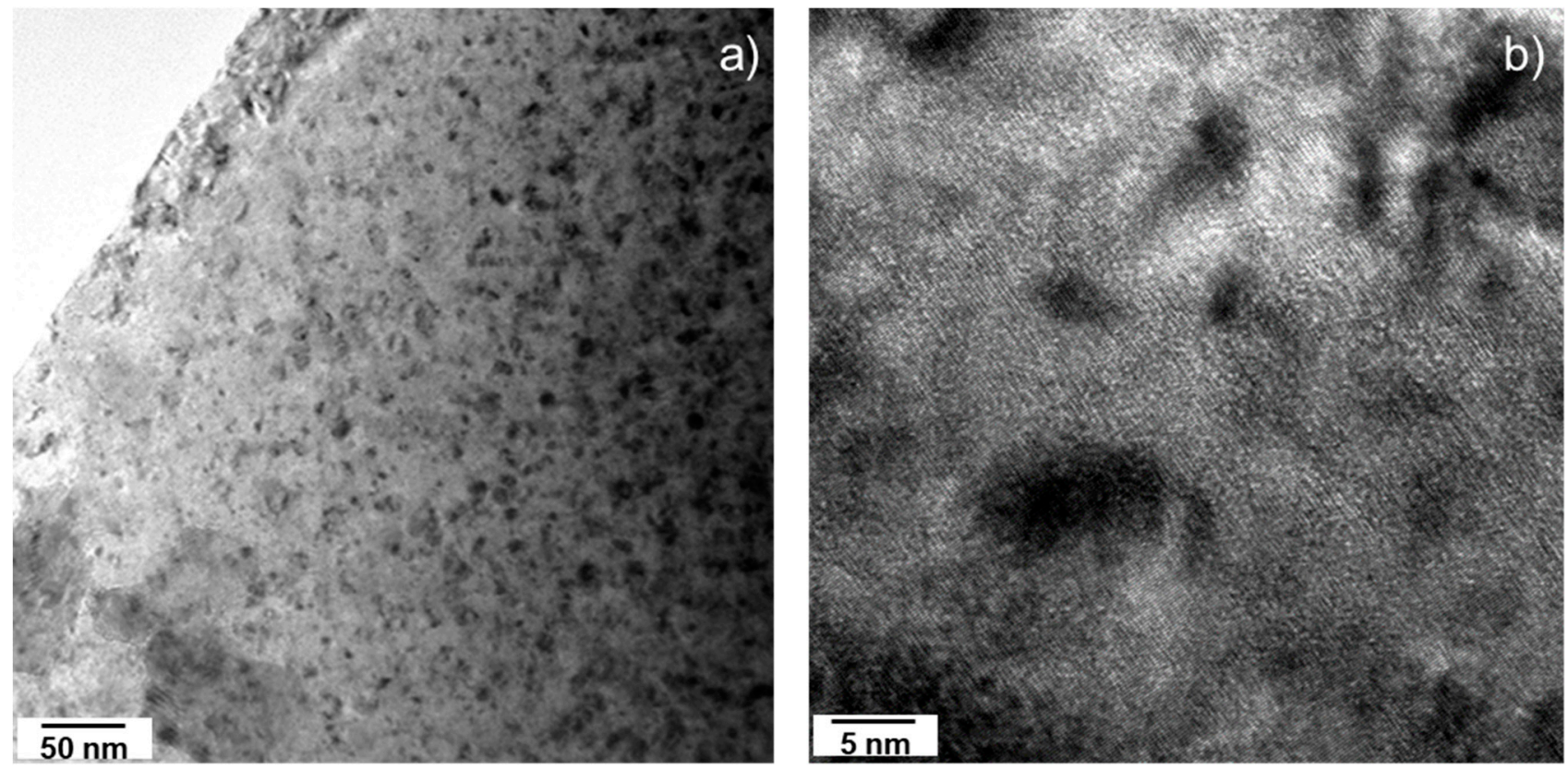

Figure 9. TEM bright field micrographs of sample UPuO-10 (4 dpa) showing (a) dislocation loops of 5 nm or more, and (b) details on higher magnification showing nanometric and sub-nanometric helium bubbles (white spots) and defect (interstitial) clusters (small black dots of 1-2 nm).

\subsubsection{Irradiated $\mathrm{UO}_{2}$ Fuels- 0.1 Dpa}

In this section, we intend to show that an irradiated fuel microstructure, whatever the experimental conditions (light water reactor vs. fast reactor technology), can share some similarities with alpha-doped materials.

In a very similar approach to the SUPERFACT SF14 sample case, the dpa considered here were accounted only after irradiation. In the case of the examined LWR fuels, it was in the order of 0.1 dpa, i.e., much lower than SUPERFACT SF14 (15.9 dpa). However, the nature of the damage observed was very similar to what is observed in alpha-doped materials. The size of the observed loops was very close to $10 \mathrm{~nm}$, which is larger than what is observed in the alpha-doped materials examined here. In addition to dislocation loops, one can also observe some dislocation lines and fission gas bubbles. Evidently, the microstructure is not solely due to the alpha damage accumulated during storage but also from the irradiation. Indeed, dislocation lines resulting from irradiation are observed in most irradiated fuels and their presence is attributed to precipitation and the interaction of loops, or to thermo-mechanical stresses. However, no TEM examinations took place at the discharge of any irradiated fuel and the annealing of the dislocation loop was found in alpha-doped $\mathrm{UO}_{2}$ at a temperature of $900 \mathrm{~K}$. The three fuels, for which TEM micrographs are shown in Figure 10a-c, were irradiated at temperatures higher than $900 \mathrm{~K}$ and revealed 
the presence of dislocation loops. It should be noted that the linear power, reactor shut down and scram, and the radial position (hence, temperature experienced) all play a role in the microstructure of the fuel at discharge, but it is outside the scope of this paper to discuss these aspects. Some general description of the fuel microstructure as a function of burnup and irradiation temperatures can be found in [34,37]. It can be argued that the nature of TEM-observable (extended) defects is very similar in stored irradiated fuel and alpha-damaged actinide dioxides, except for dislocation lines.
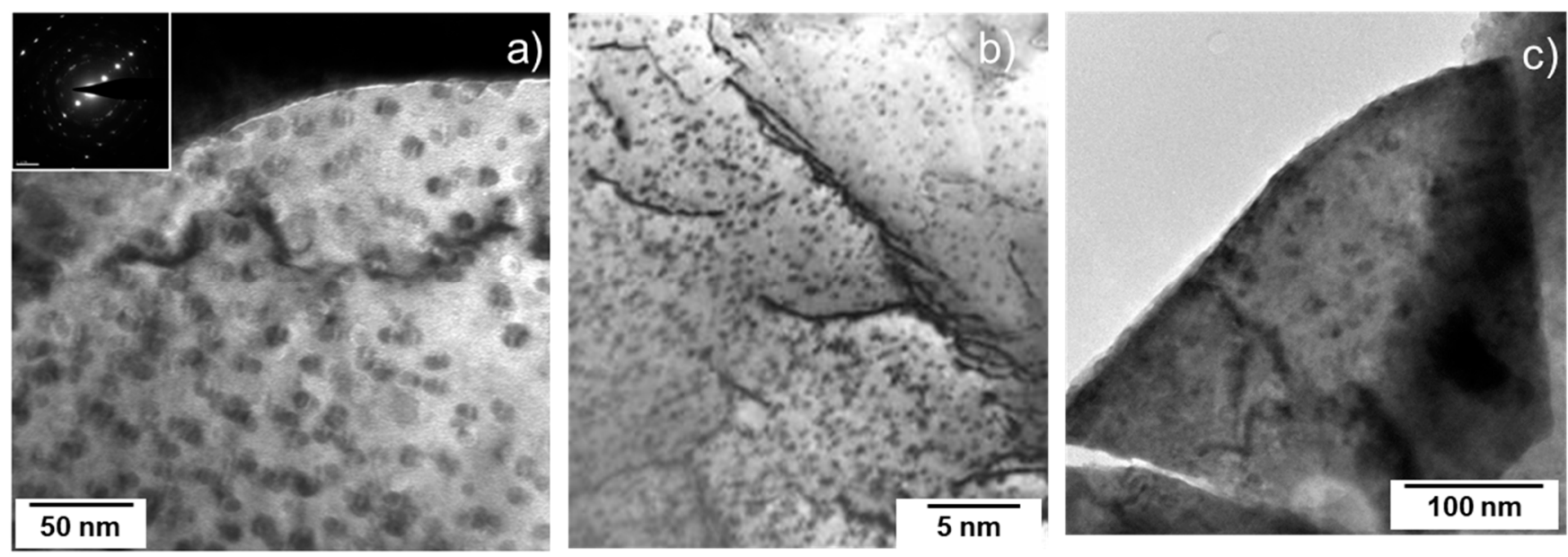

Figure 10. TEM bright field micrographs of $\mathrm{UO}_{2}$ fuel irradiated at; (a) $70 \mathrm{GWd} . \mathrm{t}^{-1}$; (b) $34 \mathrm{GWd} . \mathrm{t}^{-1}$, and (c) $58 \mathrm{GWd} . \mathrm{t}^{-1}$. For all samples, the cooling before examination led to the accumulation of approximately $0.1 \mathrm{dpa}$.

\section{Discussion}

This study is focused on microstructure evolution as a function of the cumulated alpha damage formed in spent fuel surrogates, and it complements the assessments made on kinetic effects from alpha damage and, in particular, from studies of ${ }^{238} \mathrm{Pu}$-doped $\mathrm{UO}_{2}[18,38]$. Both of those works showed that within the range of initial alpha activity studied there is a linearity in the measured properties (hardness, lattice parameter increase, thermal diffusivity, etc.), meaning that there is no dose rate effect, at least for the specific activities under study.

The main microstructure characteristics of alpha-damaged actinide dioxides with a fluorite structure consist of the formation of dislocation loops as extended defects whose size distribution and density vary with the accumulated alpha dose $[13,17,25,36,39]$.

The dislocation loops' size and density for the samples of this study were not assessed, due to the way the samples were prepared, i.e., by the crushing of small fragment. These samples were not suitable for a double-tilt TEM sample holder due to the risk of losing a radioparticle in the column, hence crystallographic analyses of the loops' characteristics (Burgers vector, habit plane) become extremely difficult. Indeed, a certain fraction of the loops could be unaccounted for. It is nevertheless considered that the most probable habit plane would be $\{110\}$, and to a lesser extent $\{111\}$ for $\mathrm{UO}_{2}$. This has been studied, for example, in the work of Onofri et al. [40] and by Bawane et al. [41] for proton irradiated $\mathrm{ThO}_{2}$ showing a more frequent loop precipitation on the $\{111\}$ plane.

Indeed, another approach used to investigate the formation of damage in actinide dioxides, and $\mathrm{UO}_{2}$ in particular, is to make use of accelerated ion beams. For the case of alpha damage, it occurs via implantations/irradiations with helium beams (the alpha particle) or with heavy atoms at energies of approximately a few hundred kiloelectronvolts to simulate the recoil nucleus. Some of these works will be described to make comparisons with the results obtained in this study. It should be emphasized that the dose rate from accelerated beams is an order of magnitude one hundred times larger than those from alpha-doped materials. At certain alpha doses, whether in ion (He)-irradiated materials or in alpha-doped materials, helium bubbles can be observed by TEM. As a very rough conver- 
sion factor, one can assume an equivalence of $5 \times 10^{18} \mathrm{He}$-at. $\mathrm{g}^{-1}$ in alpha-doped materials for $0.1 \mathrm{at} \%$ in implanted specimens. Several implantation studies of helium in $\mathrm{UO}_{2}$ were performed and bubbles were observed [42-45]. Recently, A. Michel performed a thorough TEM investigation of the He bubble precipitation in $\mathrm{UO}_{2}$ [46]. The author implanted two specimens at $7 \times 10^{16} \mathrm{He}$-ions $\mathrm{cm}^{-2}$ at $200{ }^{\circ} \mathrm{C}$ and at a fluence of $3 \times 10^{17} \mathrm{at}_{\mathrm{cm}}^{-2}$ at $700{ }^{\circ} \mathrm{C}$, resulting in a concentration of 0.03 and 0.15 at $\%$ corresponding to 0.05 and $0.24 \mathrm{dpa}$, respectively, at the implantation depth, therefore close to our sample, UPuO-5. The main conclusion of his work was related to helium bubbles and focused ion beam artefacts being the possible interferences for the measurement with features below $0.4 \mathrm{~nm}$. However, it was demonstrated that no (visible) helium bubbles formed at a concentration of 0.05 at $\%$ in $\left(\mathrm{U}_{0.8}, \mathrm{Pu}_{0.2}\right) \mathrm{O}_{2}$ single crystals [46]. The particular aspect of helium bubbles is not discussed here, particularly when studied on ion-implanted samples, i.e., only the alpha particle effect. It is more probable that a heterogeneous precipitation of bubbles is predominant in alpha-doped (and reactor-irradiated) samples due to the formation of defects by the recoil nucleus in particular. In addition, it can be noted that the alpha particle does not generate a relevant amount of displacements compared to the recoil nucleus, as previously mentioned in Section 2.4 .

The damage aspect, which was the main point of focus of this study, can be supported by some observations made on ion-implanted/-irradiated samples, typically for $\mathrm{UO}_{2}$. The main defects observed by TEM in our study consisted of dislocation loops as described in Section 3. The dislocation evolution of a $\mathrm{UO}_{2}$ single crystal implanted with $\mathrm{Kr}$ was studied by $\mathrm{He}$ et al. [29] who showed that, whereas low irradiation doses result in nucleation and the growth of dislocation loops, high doses cause a transformation into large dislocation lines and networks, as well as a shrinkage and even a disappearance of some dislocations and loops due to high temperature annealing. In general, the behaviour of dislocations in $\mathrm{Kr}$ irradiated $\mathrm{UO}_{2}$ was similar for both combinations of ion energy and temperature they used $\left(150 \mathrm{keV}\right.$ at $600{ }^{\circ} \mathrm{C}$ and $1 \mathrm{MeV}$ at $\left.800^{\circ} \mathrm{C}\right)$.

The highest dislocation loop density measured was around $5 \times 10^{14}$ ions $\mathrm{cm}^{-2}$. Some dislocation loops started to transform into dislocation segments around $1 \times 10^{15}$ ions cm $\mathrm{cm}^{-2}$ (13 dpa), eventually evolving into tangled networks at higher doses through coalescence/coarsening mechanisms, as was also observed at 44 dpa by Haddad et al. [27]. This observation is in agreement with the microstructure observed in SF14, i.e., at $16 \mathrm{dpa}$, where some dislocation loops co-exist with dislocation segments, probably resulting from coalescence.

Onofri et al. [40] irradiated polycrystalline thin foils with either $4 \mathrm{MeV}$ Au- or $390 \mathrm{keV}$ Xe-ions at different temperatures $\left(25,600\right.$, and $\left.800{ }^{\circ} \mathrm{C}\right)$ and fluences $\left(0.5\right.$ and $1 \times 10^{15}$ ions $\mathrm{cm}^{-2}$ ) to fully characterize both dislocation loops and lines induced by ion-irradiations in $\mathrm{UO}_{2}$. TEM analysis was employed to determine their Burgers vectors, habit/slip planes, and interstitial or vacancy nature.

Their investigation, carried out on a large number of dislocation loops sized between 10 to $80 \mathrm{~nm}$, as well as for the first time on a number of dislocation lines, discovered unfaulty prismatic dislocation loops of interstitial nature, with Burgers vectors positioned along the $<110>$ directions only.

In a later work, in situ TEM analysis was employed by Onofri et al. [47] to study the effect of temperature on dislocations in pre-irradiated, polycrystalline $\mathrm{UO}_{2}$ foils.

Whereas initially dislocation loops were only observed due to low temperature and low fluence irradiation, a second set of small ( $<5 \mathrm{~nm}$ in diameter) dislocation loops appeared at around $500{ }^{\circ} \mathrm{C}$. The cause may be the dislocations acting as sinks for point-defect recovery. In the case of both dislocation lines and irradiation-induced loops being initially present, strong line rearrangements by slipping took place, particularly around $800{ }^{\circ} \mathrm{C}$. Then, regardless of the initial irradiation conditions, a second annealing phase related to extended defect recovery was detected at above $1000-1100{ }^{\circ} \mathrm{C}$.

The density of dislocations, both of the loop and line variety, decreased with increasing temperature. 
In the recent work of Onofri et al. [47], the temperature effect was clearly demonstrated. A direct correlation with our observations was made on a purely qualitative aspect. The damage level in the thin foil irradiated by Onofri et al. was in the order of magnitude of that observed in the irradiated LWR fuels, i.e., $0.1 \mathrm{dpa}$. The evolution of dislocation loops into dislocation lines at $500{ }^{\circ} \mathrm{C}$ supports our assumption that the extended defects produced at irradiation at $630{ }^{\circ} \mathrm{C}$ would consist mainly of dislocation lines and that the observed dislocation loops are formed during storage.

In the case of alpha decay, there is a mix of elastic and inelastic energy loss from the recoil nucleus and alpha particle, respectively, compared to ion-irradiations. However, recently, ion-irradiation experiments attempted to discriminate between the contributions of both (sequentially and simultaneously) to the formation of defects.

Following the irradiation by two different beams (900 keV I and $27 \mathrm{MeV} F e$, hereafter referred to as Se and Sn, respectively), both a lower point defect density and lower strain levels were observed; nevertheless, TEM results pointed out that electronic ionizations modify the defects generated by nuclear collisions [31]. An evolution from dislocation loops generated by single Sn irradiation to dislocation lines in the case of dual beam irradiation is indeed found for a similar Sn fluence.

The lattice appears to heat up, through an electron-phonon coupling, enough to increase local defect mobility. The next step would be for dislocation loops to trap smaller defects and therefore increase their size until dislocation lines originate. These findings point to a modification of the $\mathrm{UO}_{2}$ matrix, induced by the combination of electronic energy loss and defects created by nuclear energy loss. [31]. This study reported, for the first time, the concomitant effect of Sn and Se using implantation. However, the ratio between Sn and Se in alpha decay remains rather low, so that the Sn effect should remain dominant. Indeed, in the study by Bricout et al. [31], the Sn/Se ratio was approximately 0.23 , whereas for alpha decay, this ratio was approximately $\mathrm{Sn} / \mathrm{Se}=0.05$. It is not expected that alpha particles can cause any substantial displacement cascades, but rather by thermal spike effect in $\mathrm{UO}_{2}$ they promote the diffusion of defects in addition to the displacement cascades generated by the recoil nucleus. The study by Ferry et al. [48] on the self-alpha irradiation-induced diffusion of oxygen and uranium describes the thermal effects and displacement cascades from the recoil nucleus as both having a contribution to the mobility of uranium and oxygen, and so we can assume that it could promote some growth of dislocation loops.

Primary radiation damage in $\left(\mathrm{U}_{1-y}, \mathrm{Pu}_{\mathrm{y}}\right) \mathrm{O}_{2}$ solid solution was also studied through molecular dynamics simulations for various temperatures and plutonium contents [7,49].

This assessment was performed in four parts: (a) defect formation energies, (b) Frenkel pair recombination, (c) displacement cascades, and (d) modelling the dose effect by the Frenkel pair accumulation method.

Primary damage behaves in the same way with respect to increasing the dose, as previously observed in pure $\mathrm{UO}_{2}$. First, point defects are created. They eventually cluster and form small Frank loops, which in turn grow into unfaulty loops. The study also put into evidence the effects of plutonium content, showing that dislocation density decreases as plutonium content increases when using the Cooper potential, due to a higher degree of Frenkel pair recombination [7]. During irradiation in the reactor, the fuels cumulate a very high level of damage from the fission spikes [25]. Point defects, as well as extended defects (dislocation loops and lines) are formed and evolve as a function of the irradiation temperature in different microstructure, including the so-called High Burnup Structure (HBS), evidently associated to the formation of large amounts of defects [37,50-52].

In order to analyse nuclear fuel reaching the end of its in-pile life, no examination can take place in a hot cell before the fuel has cooled down. Since the irradiated fuel has a residual large alpha activity component, to assess its properties when examined out of pile, the material degradation that occurs during cooling has to be taken into account. Alpha-doped samples are very valuable in this respect, since, in their case, the effect of low-temperature cumulated alpha-decay damage can be independently studied [22]. 
G. Brindelle clearly evidenced that, during storage, an increase in alpha damage (three thermal releases were performed on samples from the same fuel but stored for different times) impacts the release behaviour of xenon during thermal annealing [32]. This finding confirms that the fuel is not in a steady state and that the damage evolves over a time scale of only a few years. The exact nature of the defects, although not studied by TEM, nevertheless confirm that defects responsible for migration (in these cases, gases) are produced and would therefore also certainly contribute to the evolution of the spent fuel [32].

Haddad et al. performed implantations of $\mathrm{UO}_{2}$ single crystals with $470 \mathrm{keV} \mathrm{Xe}$ or $500 \mathrm{keV} \mathrm{La}$ at $773 \mathrm{~K}$ and fluences between $10^{13}$ and $10^{16}$ ions $\mathrm{cm}^{-2}$ to investigate, through Rutherford Backscattering in Channelling mode (RBS-C), how radiation damage and the incorporation of extraneous elements affect matrix behaviour. In situ TEM images show the appearance and evolution of several defects as a function of the ion dose up to $44 \mathrm{dpa}$, regardless of the chemical nature of the bombarding ion: 'black dot' defects, dislocation loops and lines at first, then a dislocation network at a higher dpa [27].

These results from the ion-implantation studies can be compared to our results. The basic mechanisms of damage formation, whether produced by implantation or by decay, will be of the same nature providing the energy and mass of the considered ion are the same, or in better words the energy loss is the same. For the recoil nucleus, it is predominantly nuclear, whereas for the alpha particle, the electronic energy losses are predominant [26]. The type of residual defects and their evolution are dependent on dose rate, temperature, elemental composition, and stoichiometry of the compound. The current study showed that (observable) defects produced by alpha decays in actinide oxides of different composition are of the same nature (dislocation loops and lines) within the studied dose rates. A thorough description of the evolution of the defects would require integrating the point defects. This can be obtained from X-ray diffraction data (lattice parameter), which are impacted by the two classes of defects (point and extended). The results of a former study on the defects formed at low damage level, and their impact on thermal diffusivity has been previously published [53]. In the specific case of the SUPERFACT samples studied in this paper, the damage that has been reached (more than $1 \mathrm{dpa}$ ) is beyond the threshold for which the saturation (increases between approximately 0.3 and $0.4 \%$ ) of the lattice parameter is observed for several actinide oxide compounds [12,13,18,54-58]. The steady state in the creation and annealing of point defects has been the main explanation of the saturation of the lattice parameter. The kinetic aspects are of importance, and it has been shown recently that within the dose ranges studied here the behaviour was linear [18]. After saturation of the lattice parameter (at approximately $1 \mathrm{dpa}$ ), an increase in dislocation loops size was observed, and it could be demonstrated that while strain increased, the micro-strain decreased in alpha-doped samples (isotropic damage).

In particular, in our study the SF4 sample and UPuO-10, with 4.9 and 4 dpa, respectively, compared very well to each other. This qualitative assessment of the self-damage associated to alpha decay in materials definitely needs more precise quantification. Single effect studies such as ion-implantations show a very similar trend in the microstructure evolution of alpha damage in $\mathrm{UO}_{2}$ and, in particular, due to the recoil nucleus, they show the main contributor to defect formation, which compares favourably in terms of dpa.

To this extent, the irradiated SUPERFACT SF14 constitutes an extremely highly damaged fuel, equivalent to LWR standard fuels aged by more than $1 \mathrm{Ma}$, that remain integral despite the amount of radiogenic helium and damage generated. No single effect studies have (yet) combined both helium and equivalent recoil nucleus doses to this extent, therefore, this study constitutes a first approach to predicting the real spent fuel behaviour over long storage times.

The dose rates for the alpha-doped materials, including the SUPERFACT samples, remain low compared to ion-implantations/irradiations. However, they are themselves extremely low compared to the activities of standard LWR fuels, either $\mathrm{UO}_{2}$ or MOX fuels. In a previous study [13], we revealed that the microstructure of alpha-doped materials and 
very old uraninites or thorianites compare well. One of the conclusions of that paper was related to the possible accommodation of radiogenic helium in the fuel microstructure. It was shown from the TEM investigation of the SF14 sample that no evident micro-cracking developed despite very large amounts of helium and defects generated. The SF14 sample was very porous due to the irradiation temperature, and could therefore retain a high quantity of the newly formed helium. No mechanical properties were measured nor XRD performed on the SUPERFACT samples in general, but as evidenced by the recent studies on alpha-doped materials [18], with increasing alpha dose, the micro-strain reduces, most probably because of the saturation of point defect formation and precipitation, growth of dislocation loops and the further saturation of dislocation lines.

\section{Conclusions}

Actinide dioxides with the fluorite structure can be used for the prediction of LWR spent nuclear fuel behaviour over an extended storage time or even over disposal times. The SUPERFACT experiment, performed in the mid-1980s, constituted the first transmutation test of minor actinides in a fast reactor. The materials tested were $\mathrm{UO}_{2}$-based ceramics with various amount of the minor actinides to be transmuted (Am, Np).

The observed microstructure presents very strong similarities, in particular regarding the formation of dislocation loops and of nanometric helium bubbles, to what was found by previous studies on ${ }^{238} \mathrm{Pu}$-doped $\mathrm{UO}_{2}$ samples, in which the ageing of such fluorite compounds was also accelerated. It was previously demonstrated that for ${ }^{238} \mathrm{Pu}$-doped $\mathrm{UO}_{2}$, a difference of a factor of 100 in activity does not affect the linearity of some properties related to damaging effects. The current work shows that microstructure evolution follows a similar profile independently of the studied dose, and thus corroborates this finding and extends the range of materials to study from the ageing of spent LWR fuel to minor actinide doped $\mathrm{UO}_{2}$.

The irradiated SUPERFACT transmutation fuel constitutes an even more representative material because it has been irradiated and hence contains fission products and reactor irradiation damage. Despite the similarity with irradiated fuels, it also differs substantially because of the initial (and final) composition in terms of minor actinide content (much higher). The burnup was equivalent to commercial LWR fuel, but the irradiation temperature was much higher, which in turn can constitute a difference in terms of the healing of defects during irradiation, the precipitation of secondary phases, and the behaviour of volatile species.

From the microstructure observations of the different materials of this study, and those made in previous ones, it can be argued that the linear behaviour regarding damage effects could be used to extrapolate the evolution of commercial spent fuel over very long time spans. For the highest dpa studied here, and in particular that of a reactor-irradiated material corresponding to a standard LWR fuel aged more than one million years, it has been shown that the material preserves its integrity and that the microstructure is characterised mainly by the presence of extended defects. Some limitations are intrinsic to the studied materials, whose actinide content does not reflect the reality of real spent fuel, particularly in the case of the irradiated SUPERFACT SF14 fuel, which presented a relatively large porosity formed during irradiation that could accommodate a substantial amount of helium.

Author Contributions: Investigation, T.W., O.D., E.D.B., R.K., V.R. and A.B.; writing-original draft preparation, T.W. and O.D.; writing-review and editing, T.W., O.D., E.D.B., A.B., R.K. and V.R. All authors have read and agreed to the published version of the manuscript.

Funding: This research received no external funding.

Institutional Review Board Statement: Not applicable.

Informed Consent Statement: Not applicable. 
Data Availability Statement: The data presented in this study are available on request from the corresponding author.

Acknowledgments: The authors would like to express their thanks to Dimitri Papaioannou, Detlef Wegen, Gérard Montagnier, and Komlan Anika for the sample preparation in the hot cells, Didier Pellotiero, Bert Cremer, and Markus Ernstberger for the support for the microscopy observations.

Conflicts of Interest: The authors declare no conflict of interest.

\section{Appendix A. Elemental Evolution of the SUPERFACT Samples with Time: EELS Analysis}
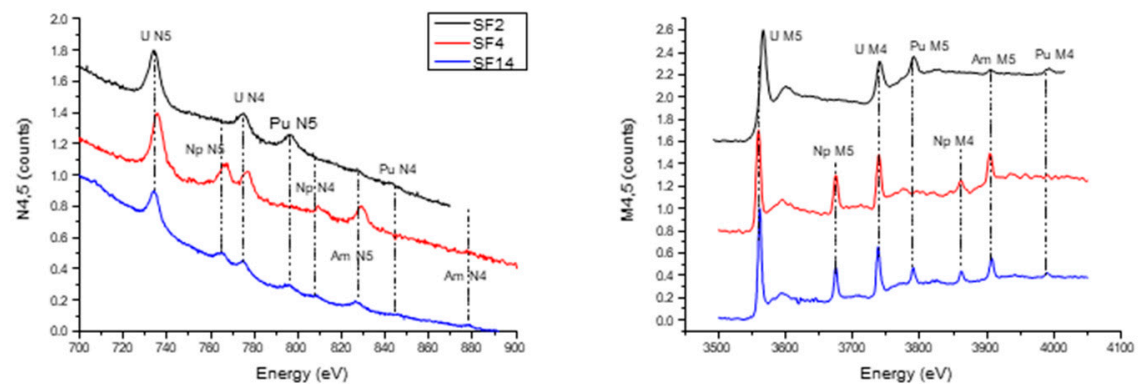

Figure A1. Different regions of the EELS spectrum for each SUPERFACT sample; the $\mathrm{M}_{4,5}$ and $\mathrm{N}_{4,5}$ edges (used for quantification) for each element are indicated.

The data available for the elemental composition of the SF14 relied mainly on calculations. Advantage was taken of the EELS to assess the composition of the studied samples. The first sample studied, SF2, had a low content of Am and high content of $\mathrm{Pu}(24$ at $\%$ $\mathrm{Pu}$ MOX with 2 at\% Am). This sample was not irradiated, and thus the storage time was slightly longer than the irradiated one. The calculated alpha damage was $1.3 \mathrm{dpa}$; although a large amount of $\mathrm{Pu}$ was present, the majority of it was ${ }^{239} \mathrm{Pu}$ with a very long half-life $(24,110 \mathrm{y})$ so it did not contribute largely to the alpha damage. ${ }^{240} \mathrm{Pu}$ is also not very alpha active, as the half-life is $6564 \mathrm{y} .{ }^{241} \mathrm{Pu}$ decays to ${ }^{241} \mathrm{Am}$ by beta, and thus the alpha damage from this decay was zero. Finally, ${ }^{242} \mathrm{Pu}$ is almost stable, with a half-life of $375 \mathrm{ka}$. All in all, among all the plutonium isotopes, only the 0.6 at $\%{ }^{238} \mathrm{Pu}$ would contribute extensively to alpha damage. The damage is essentially produced by ${ }^{241} \mathrm{Am}$ from the original material and decay product from ${ }^{241} \mathrm{Pu}$.

The second sample, SF4, contained 20 at $\%$ Am and 20 at $\%$ Np (designated Am20Np20). Almost all the damage came from the ${ }^{241} \mathrm{Am}$ which decays to ${ }^{237} \mathrm{~Np}$, thus the amount of Am was reduced and the $\mathrm{Np}$ increased. Furthermore, a small amount of ${ }^{235} \mathrm{U}$ decays. Due to the high content in ${ }^{241} \mathrm{Am}$, the cumulated damage in this sample was higher than on the previous, reaching $4.9 \mathrm{dpa}$.

The third sample, SF14, was the same as the previous sample, SF4, but taken after irradiation in the Phénix reactor. During irradiation, the elemental isotopic composition changed, producing a variety of isotopes. Among them, ${ }^{238} \mathrm{Pu}$ would produce the majority of the damage due to its reduced half-life (89 y) and ${ }^{242} \mathrm{Am}$ (with a short half-life of only $16 \mathrm{~h}$ ), which decays to ${ }^{238} \mathrm{Pu}$, increasing the effect of this isotope. Due to the high temperature reached during the irradiation, all alpha damage accumulated between the production date and the end of the irradiation was annealed, and all the helium associated released [2]. Notwithstanding, the alpha activity of the ${ }^{242} \mathrm{Am}$ and the ${ }^{238} \mathrm{Pu}$, together with the ${ }^{241} \mathrm{Am}$ and ${ }^{237} \mathrm{~Np}$ (and the ${ }^{241} \mathrm{Am}$ created by the decay of ${ }^{241} \mathrm{Pu}$ via $\beta$ ) led to an accumulated damage of 15.9 dpa.

The EELS spectra on this sample were very clear, showing the N4,5 edges and M4,5 perfectly separated and allowing us to carry out a semi-quantitative elemental analysis. Table 2 shows the ratios of all the actinides observed, providing a very accurate result. 
The O4,5 edges of all the actinides were overlapping, and thus it is was not possible to observe them independently. There was, though, a drift on the position of the edges, which moves from lower values for the first sample to higher on the last one.

The oxygen $\mathrm{K}$ line was obtained in order to see if the average oxidation state of the sample could be, to some extent, evaluated. The shape of these spectra was basically identical, except for a small observed drift, which could not be related to any change in properties.

The quantitative analyses are reported in Table 2.

\section{References}

1. Carbol, P.; Wegen, D.H.; Wiss, T.; Fors, P.; Jegou, C.; Spahiu, K. Spent nuclear fuel as waste material. In Comprehensive Nuclear Materials, 2nd ed.; Konings, R.J.M., Stoller, R.E., Eds.; Elsevier: Oxford, UK, 2020; pp. 347-386.

2. Prunier, C.; Boussard, F.; Koch, L.; Coquerelle, M. Some Specific Aspects of Homogeneous Americium- and Neptunium-Based Fuels Transmutation Through the Outcomes of the Superfact Experiment in Phénix Fast Reactor. Nucl. Technol. 1997, 119, 141-148. [CrossRef]

3. Weber, W.J.; Ewing, R.C.; Vance, E.R.; Gregg, D.; Peuget, S.; Wiss, T. Plutonium in waste forms. In Plutonium Handbook; Clark, D.L., Geeson, D.A., Hanrahan, J.R.J., Eds.; American Nuclear Society: La Grange Park, IL, USA, 2019; pp. $1360-2376$.

4. Ziegler, J.F.; Ziegler, M.; Biersack, J. SRIM-The stopping and range of ions in matter. Nucl. Instrum. Methods Phys. Res. Sect. B Beam Interact. Mater. Atoms 2010, 268, 1818-1823. [CrossRef]

5. Soullard, J.; Alamo, A. Etude du ralentissement des ions dans une cible diatomique. Radiat. Eff. 1978, 38, 133-139. [CrossRef]

6. Kinchin, G.H.; Pease, R.S. The Displacement of Atoms in Solids by Radiation. Rep. Prog. Phys. 1955, 18, 1-51. [CrossRef]

7. Balboa, H.; Van Brutzel, L.; Chartier, A.; Le Bouar, Y. Damage characterization of $(\mathrm{U}, \mathrm{Pu}) \mathrm{O}_{2}$ under irradiation by molecular dynamics simulations. J. Nucl. Mater. 2018, 512, 440-449. [CrossRef]

8. Burakov, B.E.; Yagovkina, M.A.; Zamoryanskaya, M.V.; Kitsay, A.A.; Garbuzov, V.M.; Anderson, E.B.; Pankov, A.S. Behavior of ${ }^{238} \mathrm{Pu}$-Doped Cubic Zirconia under Self-Irradiation. MRS Online Proc. Libr. Arch. 2003, 807, 571-575. [CrossRef]

9. Burakov, B.E.; Ojovan, M.I.; Lee, W.E. Crystalline Materials for Actinide Immobilisation; World Scientific: Singapore, 2011 ; Volume 1.

10. Ojovan, M.I.; Burakov, B.E.; Lee, W.E. Radiation-induced microcrystal shape change as a mechanism of wasteform degradation. J. Nucl. Mater. 2018, 501, 162-171. [CrossRef]

11. Burakov, B.; Yagovkina, M. A study of accelerated radiation damage effects in $\mathrm{PuO}_{2}$ and gadolinia-stabilized cubic zirconia, $\mathrm{Zr}_{0.79} \mathrm{Gd}_{0.14} \mathrm{Pu}_{0.07} \mathrm{O}_{1.93}$, doped with ${ }^{238} \mathrm{Pu}$. J. Nucl. Mater. 2015, 467, 534-536. [CrossRef]

12. Wiss, T.; Dieste-Blanco, O.; Tacu, A.; Janssen, A.; Talip, Z.; Colle, J.-Y.; Martin, P.; Konings, R. TEM study of alpha-damaged plutonium and americium dioxides. J. Mater. Res. 2015, 30, 1544-1554. [CrossRef]

13. Wiss, T.; Hiernaut, J.-P.; Roudil, D.; Colle, J.-Y.; Maugeri, E.; Talip, Z.; Janssen, A.; Rondinella, V.; Konings, R.J.; Matzke, H.-J. Evolution of spent nuclear fuel in dry storage conditions for millennia and beyond. J. Nucl. Mater. 2014, 451, 198-206. [CrossRef]

14. De Bona, E.; Benedetti, A.; Dieste, O.; Staicu, D.; Wiss, T.; Konings, R. Radiation effects in alpha-doped $\mathrm{UO}_{2}$. Nucl. Instrum. Methods Phys. Res. Sect. B Beam Interact. Mater. Atoms 2020, 468, 54-59. [CrossRef]

15. Rondinella, V.; Cobos, J.; Matzke, H.; Wiss, T.; Carbol, P.; Solatie, D. Leaching Behavior and $\alpha$-Decay Damage Accumulation of $\mathrm{UO}_{2}$ Containing Short-Lived Actinides. Mat. Res. Soc. Symp. Proc. 2001, 663, 392-399. [CrossRef]

16. Staicu, D.; Wiss, T.; Rondinella, V.; Hiernaut, J.; Konings, R.; Ronchi, C. Impact of auto-irradiation on the thermophysical properties of oxide nuclear reactor fuels. J. Nucl. Mater. 2010, 397, 8-18. [CrossRef]

17. Jonnet, J.; Van Uffelen, P.; Wiss, T.; Staicu, D.; Remy, B.; Rest, J. Growth mechanisms of interstitial loops in $\alpha$-doped UO 2 samples. Nucl. Instrum. Methods Phys. Res. Sect. B Beam Interact. Mater. Atoms 2008, 266, 3008-3012. [CrossRef]

18. De Bona, E.; Colle, J.-Y.; Dieste, O.; Cologna, M.; Wiss, T.; Baldinozzi, G.; Konings, R.J.M. Self-irradiation-induced disorder in $\left(\mathrm{U}^{238} \mathrm{Pu}\right) \mathrm{O}_{2}$. MRS Adv. 2021, 1-7. [CrossRef]

19. Fernandez, A.; Richter, K.; Somers, J. Fabrication of transmutation and incineration targets by infiltration of porous pellets by radioactive solutions. J. Alloys Compd. 1998, 271, 616-619. [CrossRef]

20. Walker, C.; Nicolaou, G. Transmutation of neptunium and americium in a fast neutron flux: EPMA results and KORIGEN predictions for the SUPERFACT fuels. J. Nucl. Mater. 1995, 218, 129-138. [CrossRef]

21. Babelot, J.-F.; Chauvin, N. Joint CEA/ITU Synthesis Report of the Experiment SUPERFACT 1; Technical Note JRC-ITU-TN-99/03; Institute for Transuranium Elements: Karlsruhe, Germany, 1999.

22. Wiss, T.; Thiele, H.; Janssen, A.; Papaioannou, D.; Rondinella, V.V.; Konings, R.J.M. Recent Results of Microstructural Characterization of Irradiated Light Water Reactor Fuels using Scanning and Transmission Electron Microscopy. JOM 2012, 64, 1390-1395. [CrossRef]

23. Keast, V. Application of EELS in Materials Science. Mater. Charact. 2012, 73, 1-7. [CrossRef]

24. Magill, J.; Dreher, R. The NUCLEONICA Nuclear Science Portal. In Current Status, Trends and Needs in Radiochemical Education: The U.S. and Abroad; Yeisler, R., Kenan, Ü., Heller-Zeisler, S., Eds.; American Institute of Physics: Melville, NY, USA, 2009; pp. 100-106. [CrossRef] 
25. Wiss, T.; Konings, R.J.M. Radiation Effects in Actinide Compounds with the Fluorite Structure. In Properties of Fluorite Structure Materials; NOVA: New York, NY, USA, 2013; pp. 153-188.

26. Wiss, T.; Benedetti, A.; de Bona, E. 2.05-Radiation Effects in $\mathrm{UO}_{2}$, in Comprehensive Nuclear Materials, 2nd ed.; Konings, R.J.M., Stoller, R.E., Eds.; Elsevier: Oxford, UK, 2020; pp. 125-148.

27. Haddad, Y.; Delauche, L.; Gentils, A.; Garrido, F. In situ characterization of irradiation-induced microstructural evolution in urania single crystals at $773 \mathrm{~K}$. Nucl. Instrum. Methods Phys. Res. Sect. B Beam Interact. Mater. Atoms 2018, 435, 25-30. [CrossRef]

28. Sabathier, C.; Martin, G.; Michel, A.; Carlot, G.; Maillard, S.; Bachelet, C.; Fortuna, F.; Kaitasov, O.; Oliviero, E.; Garcia, P. In-situ TEM observation of nano-void formation in $\mathrm{UO}_{2}$ under irradiation. Nucl. Instrum. Methods Phys. Res. Sect. B Beam Interact. Mater. Atoms 2014, 326, 247-250. [CrossRef]

29. He, L.-F.; Gupta, M.; Yablinsky, C.; Gan, J.; Kirk, M.A.; Bai, X.; Pakarinen, J.; Allen, T. In situ TEM observation of dislocation evolution in Kr-irradiated $\mathrm{UO}_{2}$ single crystal. J. Nucl. Mater. 2013, 443, 71-77. [CrossRef]

30. Belhabib, T.; Desgardin, P.; Sauvage, T.; Erramli, H.; Barthe, M.-F.; Garrido, F.; Carlot, G.; Nowicki, L.; Garcia, P. Lattice location and annealing behaviour of helium atoms implanted in uranium dioxide single crystals. J. Nucl. Mater. 2015, 467, 1-8. [CrossRef]

31. Bricout, M.; Onofri, C.; Debelle, A.; Pipon, Y.; Belin, R.C.; Garrido, F.; Leprêtre, F.; Gutierrez, G. Radiation damage in uranium dioxide: Coupled effect between electronic and nuclear energy losses. J. Nucl. Mater. 2020, 531, 151967. [CrossRef]

32. Brindelle, G. Etude du Relâchement de Gaz de Fission Entrer $600{ }^{\circ} \mathrm{C}$ et $800{ }^{\circ} \mathrm{C}$ lors de Transitoire Thermique sur Combustible Irradié. Ph.D. Thesis, Paris-Saclay, Gif-sur-Yvette, France, 2017.

33. Buck, E.C.; Mausolf, E.J.; McNamara, B.K.; Soderquist, C.Z.; Schwantes, J. Nanostructure of metallic particles in light water reactor used nuclear fuel. J. Nucl. Mater. 2015, 461, 236-243. [CrossRef]

34. Sonoda, T.; Kinoshita, M.; Ray, I.; Wiss, T.; Thiele, H.; Pellottiero, D.; Rondinella, V.; Matzke, H. Transmission electron microscopy observation on irradiation-induced microstructural evolution in high burn-up $\mathrm{UO}_{2}$ disk fuel. Nucl. Instrum. Methods Phys. Res. Sect. B Beam Interact. Mater. Atoms 2002, 191, 622-628. [CrossRef]

35. De Bona, E. Grain Size Effects on Radiogenic Helium Gas in the Nuclear Fuel $\mathrm{UO}_{2}$, in École Doctorale $n^{\circ} 573$ INTERFACES: Approches Interdisciplinaires, Fondements, Applications et Innovation (Interfaces). Ph.D. Thesis, Paris-Saclay, Gif-sur-Yvette, France, 2019.

36. Onofri, C.; Sabathier, C.; Carlot, G.; Drouan, D.; Bachelet, C.; Baumier, C.; Gérardin, M.; Bricout, M. Changes in voids induced by ion irradiations in $\mathrm{UO}_{2}$ : In situ TEM studies. Nucl. Instrum. Methods Phys. Res. Sect. B Beam Interact. Mater. Atoms 2020, $463,76-85$. [CrossRef]

37. Wiss, T.; Rondinella, V.V.; Konings, R.J.M.; Staicu, D.; Papaioannou, D.; Bremier, S.; Pöml, P.; Benes, O.; Colle, J.-Y.; Van Uffelen, P.; et al. Properties of the high burnup structure in nuclear light water reactor fuel. Radiochim. Acta 2017, 105, 893-906. [CrossRef]

38. Rondinella, V.V.; Wiss, T.; Hiernaut, J.-P.; Staicu, D. Dose Rate Effects on the Accumulation of Radiation Damage. In Proceedings of the 11th International Conference on Environmental Remediation and Radioactive Waste Management, Parts A and B, Bruges, Belgium, 2-6 September 2007; American Society of Mechanical Engineers: New York, NY, USA, 2007; pp. $1071-1076$.

39. Rondinella, V.V.; Wiss, T.A.G.; Papaioannou, D.; Nasyrow, R. Studies on spent nuclear fuel evolution during storage. In Key Topics in Deep Geological Disposal; Conference Report; DAEF: Leipzig, Germany, 2015.

40. Onofri, C.; Legros, M.; Léchelle, J.; Palancher, H.; Baumier, C.; Bachelet, C.; Sabathier, C. Full characterization of dislocations in ion-irradiated polycrystalline $\mathrm{UO}_{2}$. J. Nucl. Mater. 2017, 494, 252-259. [CrossRef]

41. Bawane, K.; Liu, X.; Yao, T.; Khafizov, M.; French, A.; Mann, J.M.; Shao, L.; Gan, J.; Hurley, D.H.; He, L. TEM characterization of dislocation loops in proton irradiated single crystal $\mathrm{ThO}_{2}$. J. Nucl. Mater. 2021, 552, 152998. [CrossRef]

42. Sattonnay, G.; Vincent, L.; Garrido, F.; Thome, L. Xenon versus helium behavior in $\mathrm{UO}_{2}$ single crystals: A TEM investigation. J. Nucl. Mater. 2006, 355, 131-135. [CrossRef]

43. Garcia, P.; Gilabert, E.; Martin, G.; Carlot, G.; Sabathier, C.; Sauvage, T.; Desgardin, P.; Barthe, M.-F. Helium behaviour in UO 2 through low fluence ion implantation studies. Nucl. Instrum. Methods Phys. Res. Sect. B Beam Interact. Mater. Atoms 2014, 327, 113-116. [CrossRef]

44. Garrido, F.; Vincent, L.; Nowicki, L.; Sattonnay, G.; Thomé, L. Radiation stability of fluorite-type nuclear oxides. Nucl. Instrum. Methods Phys. Res. Sect. B Beam Interact. Mater. Atoms 2008, 266, 2842-2847. [CrossRef]

45. Pakarinen, J.; Khafizov, M.; He, L.; Wetteland, C.; Gan, J.; Nelson, A.; Hurley, D.H.; El-Azab, A.; Allen, T.R. Microstructure changes and thermal conductivity reduction in $\mathrm{UO}_{2}$ following $3.9 \mathrm{MeV} \mathrm{He}^{2+}$ ion irradiation. J. Nucl. Mater. 2014, 454, 283-289. [CrossRef]

46. Michel, A. Etude de la Précipitation de l'hélium dans les Combustibles Nucléaires $\mathrm{UO}_{2}$ et $(\mathrm{U}, \mathrm{Pu}) \mathrm{O}_{2}$ en Condition de Stockage, in Ecole Doctorale 352_Physique et Science de la Matière. Ph.D. Thesis, Aix-Marseille, Marseille, France, 2019.

47. Onofri, C.; Sabathier, C.; Baumier, C.; Bachelet, C.; Drouan, D.; Gérardin, M.; Legros, M. Extended defect change in UO 2 during in situ TEM annealing. Acta Mater. 2020, 196, 240-251. [CrossRef]

48. Ferry, C.; Lovera, P.; Poinssot, C.; Garcia, P. Enhanced diffusion under alpha self-irradiation in spent nuclear fuel: Theoretical approaches. J. Nucl. Mater. 2005, 346, 48-55. [CrossRef]

49. Rahman, M.; Szpunar, B.; Szpunar, J. Molecular dynamics study of primary radiation damage in $\mathrm{PuO}_{2}$ and $\left(\mathrm{U}_{0.5} \mathrm{Pu}_{0.5}\right) \mathrm{O}_{2}$. Comput. Mater. Sci. 2019, 166, 193-199. [CrossRef]

50. Ray, I.; Thiele, H.; Matzke, H. Transmission electron microscopy study of fission product behaviour in high burnup UO2. J. Nucl. Mater. 1992, 188, 90-95. [CrossRef] 
51. Matzke, H.; Kinoshita, M. Polygonization and high burnup structure in nuclear fuels. J. Nucl. Mater. 1997, 247, 108-115. [CrossRef]

52. Rondinella, V.V.; Wiss, T. The high burn-up structure in nuclear fuel. Mater. Today 2010, 13, 24-32. [CrossRef]

53. Staicu, D.; Wiss, T.; Ronchi, C. Thermophysical effects of radiation damage in oxide fuels. In Proceedings of the 2004 International Meeting on LWR Fuel Performance, Orlando, FL, USA, 19-22 September 2004.

54. Weber, W. Alpha-irradiation damage in $\mathrm{CeO}_{2}, \mathrm{UO}_{2}$ and $\mathrm{PuO}_{2}$. Radiat. Eff. 1984, 83, 145-156. [CrossRef]

55. Prieur, D.; Vigier, J.-F.; Wiss, T.; Janssen, A.; Rothe, J.; Cambriani, A.; Somers, J. Structural investigation of self-irradiation damaged $\mathrm{AmO}_{2}$. J. Solid State Chem. 2014, 212, 7-12. [CrossRef]

56. Noe, M.; Fuger, J. Self-radiation effects on the lattice parameter of ${ }^{238} \mathrm{PuO}_{2}$. Inorg. Nucl. Chem. Lett. 1974, 10, 7-19. [CrossRef]

57. Fuger, J.; Matzke, H. Self-radiation effects in the actinides and their compounds: Basic studies and practical implications. In Handbook on the Physics and Chemistry of the Actinides; Freeman, A.J., Keller, C., Eds.; Elsevier Science Publishers B.V.: Amsterdam, The Netherlands, 1991; pp. 641-684.

58. Eyal, Y. A Radiation Annealing Model for Maintenance of Crystallinity in Self-damage Actinide dioxides. In ICEM'97, Radioactive Waste Management and Environmental Remediation; Baker, S.S.R., Benda, G., Eds.; ASME: New York, NY, USA, 1997. 